\title{
RAZONES JURÍDICAS. RESPUESTA A CARACCIOLO, CELANO Y MORESO
}

María Cristina Redondo

CONICET, Argentina

En las siguientes páginas intentaré responder a algunas de las observaciones que Ricardo Caracciolo, Bruno Celano y José Juan Moreso han realizado al artículo sobre "Razones y normas" publicado en este número de Discusiones. Antes de comenzar mi respuesta quisiera expresar que es para mí un honor y un gran placer tener esta oportunidad de diálogo. Sería imposible referirme a todos los argumentos que tocan estos autores, aun cuando de cada uno de ellos he sacado provecho para corregir y dar forma más precisa a algunas de las ideas que defiendo en mi trabajo.

\section{Una discusión sobre normas derrotables. Respuesta a Ricardo Caracciolo}

1.1. En su trabajo, Ricardo Caracciolo se concentra en una discusión lógica sobre las normas derrotables. La respuesta a sus reflexiones presenta un grado considerable de dificultad porque ellas se apoyan en conceptos distintos de los que yo he presupuesto y, como resultado, conducen a problemas diversos de los que yo analizo en mi propuesta inicial.

Sólo para ofrecer dos ejemplos. En palabras de Caracciolo, yo acepto la distinción entre los dos siguientes tipos de deberes, a saber:

a) el deber concluyente (o final, o definitivo) de realizar $p$ que, por definición, no es derrotable. ....b) el deber no concluyente (no-final o no definitivo) que se puede denominar prima facie o pro tanto de realizar $\mathrm{p}$ (no es relevante aquí 
la distinción entre estas últimas categorías), el que, por definición puede ser vencido, esto es, es derrotable.

Este párrafo es ejemplar porque hace explícito que Caracciolo me adjudica algo diferente de lo que yo propongo. En atención a ello es oportuno subrayar que, si bien admito la distinción entre deber concluyente y no concluyente, tal distinción no es central en mi trabajo, mientras que la diferencia entre deber prima facie y deber pro tanto sí lo es, puesto que esta última, y no la primera, capta la diferencia ente invariabilidad y variabilidad de la relevancia, que es lo que me interesa analizar. Más adelante retornaré sobre esta cuestión.

Asimismo, según Caracciolo:

hay una cierta incoherencia en negar carácter práctico a las normas DL (derrotables lógicamente) y concederlo a las normas DS (derrotables sustancialmente).

Ello porque:

En todo caso, es claro que de las normas DS no se pueden inferir lógicamente deberes concluyentes. $\mathrm{O}$, lo que es lo mismo, el uso de la regla del modus ponens no es admisible para obtener deberes finales a partir de normas DS. Esta es una consecuencia conceptual de la propia noción de norma derrotable.

Como se ve, en la interpretación de Caracciolo yo admito dos categorías de normas derrotables: las normas derrotable lógicamente (DL) y las normas derrotables sustancialmente (DS). Del hecho que ambas son derrotables Caracciolo colige que a ninguna de ellas es aplicable la regla del modus ponens. Esta es una clara consecuencia correcta de una hipótesis errónea, i.e. la hipótesis de que existen dos tipos o categorías de normas derrotables. Según he dicho explícitamente en mi trabajo, las normas que expresan deberes superables son universales, i.e. inderrotables y sí admiten el refuerzo del antecedente y la aplicación del modus ponens, puesto que permiten inferir el consecuente deóntico, a pesar de que éste no determina aquello que, todo considerado, debe hacerse. 
Si Caracciolo ha interpretado de este modo mi propuesta ello quiere decir que yo he dado lugar a la confusión. En "Razones y Normas" he sostenido que tanto la noción de universalidad como la de derrotabilidad son ambiguas, es decir que hay más de un sentido en el que una norma puede considerarse universal y más de un sentido en el que un deber o una razón pueden ser calificados como derrotables. Sin embargo, del mismo modo en que discernir tres sentidos de universalidad predicable de las normas no debe conducirnos a suponer que hay tres tipos o categorías de normas universales, la distinción de dos sentidos de derrotabilidad no debe conducirnos a afirmar, como propone Caracciolo, que existen dos tipos o categorías de normas derrotables ${ }^{1}$. Para no generar esta posible interpretación creo que es conveniente abandonar la expresión "derrotabilidad sustancial" y hablar de superabilidad, fuerza limitada o no absoluta de los deberes impuestos por algunas normas universales, i.e. inderrotables.

En virtud de la ambigüedad de la expresión "derrotabilidad", al predicar derrotabilidad de las normas, en ocasiones se hace referencia a una característica lógica de las mismas que indica la inaplicabilidad de las reglas del refuerzo del antecedente (en adelante RA) y del modus ponens (en adelante MP). Por este motivo, puede decirse que estas normas "lógicamente derrotables" sólo prima facie establecen un deber. Las propiedades mencionadas en el antecedente no son razones invariablemente relevantes (no configuran una condición suficiente ni una condición contribuyente para obtener una consecuencia deóntica). En otras ocasiones, en cambio, al predicar derrotabilidad de las normas se hace referencia a la fuerza de los deberes que ellas establecen en sus consecuentes. En este caso, tales deberes son superables o pro tanto aun si, desde un punto de vista lógico,

\footnotetext{
${ }^{1}$ Dado que me interesa distinguir el problema de la invariabilidad-variabilidad de la relevancia de las razones del problema del mayor o menor peso de las mismas, me he detenido sólo en estos dos sentidos posibles de derrotabilidad. Sin embargo, en la literatura sobre el tema se disciernen otras nociones de derrotabilidad, y también en este caso sería inconducente pensar que ellas permiten identificar diversos tipos de normas derrotables. Al respecto, una esclarecedora discusión sobre el tema puede encontrarse en J. C. Bayón y J. Rodríguez (2003).
} 
las normas que los establecen son "inderrotables", ya que en sus antecedentes expresan propiedades invariablemente relevantes (sea suficientes o contribuyentes) para obtener las consecuencias deónticas, i.e. los deberes en cuestión.

En mi trabajo, esta distinción entre normas que sólo prima facie establecen un deber y aquellas que establecen un deber pro tanto sí es fundamental porque capta la diferencia entre el universalismo y particularismo. Sin embargo, en palabras de Caracciolo, la diferencia entre deber prima facie y pro tanto puede considerarse irrelevante en este contexto. Ello muestra que está usando estas expresiones con un significado diferente del que tienen en mi trabajo, puesto que si las usase en el mismo sentido estaría diciendo que la diferencia entre universalismo y particularismo es irrelevante en este contexto, lo cual sería realmente sorprendente en un trabajo dedicado casi exclusivamente a dicha distinción.

A riesgo de ser reiterativa, creo que merece la pena insistir en que cuando afirmo que la relación entre (A) y (Op) es la de un condicional universal o inderrotable, estoy diciendo que es un condicional estricto que expresa la necesidad de un condicional material, es decir, se trata de un condicional cuantificado universalmente respecto de las circunstancias. En este sentido sigo la caracterización de Alchourrón. Un condicional de este tipo permite expresar la idea según la cual las normas de la moral o del derecho, si son válidas, establecen en sus antecedentes una condición invariablemente relevante respecto de la calificación deóntica de una acción.

Ahora bien, a partir de esta definición, un condicional derrotable es aquel que no es -ni abierta ni encubiertamente- un condicional cuantificado universalmente respecto de las circunstancias. Por ello, cuando se predica la derrotabilidad lógica de un condicional que expresa una norma o, directamente, de una norma, se está diciendo que no le son aplicables -ni abierta ni encubiertamente- RA y MP. En este sentido, quien acepta la posibilidad de condicionales derrotables no puede seguir la propuesta de Alchourrón, visto que en su perspectiva los condicionales derrotables sí admiten, debidamente 
complementados con el conjunto de sus condiciones implícitas, la aplicación de RA y MP. En realidad, es cuanto menos paradójico afirmar que los condicionales derrotables son aquellos que no admiten RA y MP y, al mismo tiempo, afirmar que son equivalentes a condicionales que se definen como aquellos que admiten la aplicación de RA y MP, i.e. condicionales inderrotables.

Desde esta perspectiva, si A > Op expresa un condicional derrotable, la presencia de la condición (A), mencionada en el antecedente, no autoriza a obtener el consecuente $(\mathrm{Op})$, puesto que podría ser neutralizada por la presencia de otras propiedades, que no son enumerables de antemano ${ }^{2}$. He sostenido que este tipo de condicionales es adecuado para presentar la idea según la cual los principios normativos, de la moral o del derecho, no expresan en sus antecedentes condiciones invariablemente relevantes, es decir, que invariablemente contribuyan o sean suficientes para obtener la consecuencia deóntica mencionada en el consecuente. Por este motivo, se puede decir que tales normas sólo prima facie establecen un deber. Donde la expresión "prima facie", como destaca John Searle, no es un calificativo del deber sino que cumple una función adverbial ${ }^{3}$. Decir que dado (A) se debe prima facie hacer (p) puede significar que a primera vista, o según creemos, (A) es una razón (que contribuye o es suficiente) para obtener el deber de hacer (p), pero podría suceder que, bien vistas las cosas, en una ocasión individual, aun cuando (A) esté presente no haya alguna razón para hacer (p), es decir, aun cuando (A) está presente no podemos obtener la consecuencia deóntica respecto de (p).

Un enunciado como A > Op, o bien indica que (A) puede ser -en las circunstancias apropiadas- una razón a favor del deber de hacer ( $p)$, o bien enuncia las condiciones generales (A) bajo las cuales puede existir una razón para afirmar tal deber, o bien expresa nuestra creencia de que (A) es una

\footnotetext{
${ }^{2} \mathrm{Al}$ respecto véase el ensayo de J.C. Bayón, quien se refiere a este tipo de normas llamándolas "genuinamente derrotables". Cfr. J.C. Bayón y J. Rodríguez (2003), pp. 157-208.

${ }^{3}$ Cfr. J. Searle (1991), pp. 388-391.
} 
razón para sostener el deber de (p). En cualquier caso, no es un contenido inmune a revisión, y su revisión esta indefinida, es decir, no es posible identificar el conjunto completo de sus defeaters (overriders, underminers, reversers y excusers, más los meta-overriders, meta-underminers, metareversers, meta-excusers, etc). No hay una única lectura, en términos positivos, del contenido de estos condicionales deónticos generales. La tesis del particularismo con relación a ellos es negativa. Estos condicionales no son la base del razonamiento práctico, no expresan principios universales, no guían ni justifican acciones. Enunciados de este tipo pueden expresar sólo una "default position" o una "default reason" razón invariablemente relevante, ni siquiera una propiedad que tenga tendencia a constituir una razón de este tipo. Volveré sobre este punto más adelante, y también en mi respuesta al trabajo de Moreso.

1.2. En opinión de Caracciolo las normas universalmente válidas expresan una condición suficiente de un deber final o concluyente. Esta es una posición universalista posible pero distinta de la que he tomado como punto de partida en "Razones y Normas". En mi caracterización, que en esto sigue la distinción establecida por Raz, un deber absoluto es aquel de peso insuperable y un deber concluyente es aquel que se establece sólo después de haber verificado que no existen otros en conflicto o después de haber resuelto eventuales conflictos. Es decir, un deber superable puede ser concluyente, en la medida en que no sea superado por otros.

En la construcción de Caracciolo todas las normas establecen deberes concluyentes o finales y todas ellas son, en modo abierto o encubierto, condicionales estrictos. Ello es así puesto que en su propuesta sólo cabe distinguir entre aquellas normas que expresan una condición suficiente para

\footnotetext{
${ }^{4}$ Cfr. J. Dancy (1993), p. 230.

5 "Deafault reasons are reasons unless turned off by something, but other features may not be reasons unless something turns them on”. J. Dancy (1999), p. 151.
} 
un deber final, que son condicionales universales, y aquellas que expresan una condición meramente contribuyente -siempre en relación a un deber concluyente- y que son condicionales derrotables en el sentido en que Alchourrón los define. Pero debe recordarse que, en esta interpretación, los condicionales derrotables no sólo no se oponen a los condicionales inderrotables o estrictos sino que son equivalentes a ellos, una vez debidamente revisados. Esta tesis lógica, que sólo admite la distinción entre condicionales universales y condicionales derrotables interpretados como condicionales universales "enmascarados", no ofrece un lenguaje lógico que permita expresar lo que significa una generalización normativa para un particularista. Asimismo, en virtud de las definiciones propuestas, debemos aceptar que las decisiones prácticas, o bien se justifican a través de una reconstrucción lógica que -abierta o encubiertamente- es un razonamiento subsuntivo apoyado en un condicional universal, o bien no tienen una reconstrucción lógica, no se justifican. Es decir, el particularismo, o bien ofrece un modelo de justificación que no difiere del universalista, o bien no ofrece un modelo de justificación en absoluto ${ }^{6}$. Sin embargo, esta consecuencia dilemática surge sólo porque las dos únicas "reconstrucciones lógicas" que se admiten para articular una justificación se apoyan (directa o indirectamente) en un condicional deóntico universal. El hecho de que esta interpretación de los condicionales deónticos y de la justificación de las decisiones prácticas excluya la posibilidad de expresar el sentido en que, para un particularista, las generalizaciones normativas son derrotables y las decisiones son justificadas no puede ser visto como una prueba de que la propuesta particularista es insostenible; mas bien, debe ser considerado una prueba de que para comprender lo que dice el particularismo se debe abandonar esta interpretación de los condicionales y esta reconstrucción del razonamiento práctico justificativo.

${ }^{6}$ De hecho ésta es la consecuencia que normalmente se obtiene. Véase la opinión de J. Rodríguez, que en ello está de acuerdo con J.J. Moreso. Cfr. J. Rodríguez y J.C. Bayón (2003) pp. 246-7. También, por ejemplo, T. Tännsjö (1995), pp. 571-593, en pp. 578-581. 
Caracciolo critica especialmente mi no advertencia de que la forma lógica sólo sirve para captar una idea material o intuición sustancial. Sin embargo, yo estoy plenamente de acuerdo con esta tesis. Lo que no advierte Caracciolo es que la idea material que yo quiero captar es la diferencia entre una razón en sentido universalista y una razón en sentido particularista o, lo que es lo mismo, el contraste entre la tesis que afirma la invariabilidad de la relevancia de ciertas propiedades (siendo indiferente si tal relevancia es última, concluyente, superable o insuperable) y la tesis que niega dicha invariabilidad. Esta es una idea material distinta de la que Caracciolo representa. En su perspectiva, la diferencia entre inderrotabilidad e derrotabilidad lógicas sirve para captar la diferencia entre deberes concluyentes (universales) y deberes no concluyentes (también universales), es decir una distinción admisible e interesante, pero interna a una concepción universalista ${ }^{7}$. No creo que sea un error utilizar la diferencia entre condicionales estrictos y condicionales derrotables como lo propone Caracciolo. Sin embargo sí creo que es un error reconstruir de ese modo mi trabajo o pensar que de ese modo se capta la discusión universalismoparticularismo. Si se lo hace, las consecuencias que se siguen carecen de sentido porque se está empleando el mismo lenguaje (normas derrotables, normas inderrotables, deberes prima facie, etc.) con un significado diferente. Tal como afirma Caracciolo, en mi reconstrucción la diversa jerarquía de las normas no se traduce en una diversa estructura lógica. Que el deber impuesto por una norma universal sea pro tanto (superable) o absoluto (insuperable) nada tiene que ver con la forma lógica de la norma que lo establece. En cambio, dichas estructuras sí capturan la diferencia sobre la que me interesa centrar la atención y que, en mi opinión, distingue una posición particularista de una universalista respecto de las razones. Una posición es particularista si niega la tesis universalista, i.e. si niega la existencia de normas universales

\footnotetext{
${ }^{7}$ Probablemente éste sea un modo adecuado de expresar la diferencia entre reglas y principios, analizados en una perspectiva universalista.
} 
válidas que establecen razones invariables. Si acepta algún tipo de "normas" o generalizaciones deónticas, dirá que ellas son condicionales derrotables, no reducibles a condicionales estrictos. Al respecto, un defecto significativo de la reconstrucción de Caracciolo es que, en su presentación, el particularismo no es la negación del universalismo. Esto es así porque la posición universalista se presenta como irremediablemente unida a la existencia de normas universales absolutas, i.e. normas que establecen deberes finales o concluyentes, y el particularismo no está correctamente caracterizado como la posición que niega que haya normas de este tipo. Ciertamente, el particularismo niega que haya normas universales absolutas que establecen deberes finales, pero es más radical y más sutil: niega que haya normas universales en general, sea que ellas establezcan deberes finales o pro tanto, insuperables o superables.

El universalista puede conceder que el deber establecido en el consecuente de una norma no sea absoluto ni final, pero no puede conceder -sin ser auto-contradictorio- que las normas no establecen invariablemente un deber, aunque sea superable. Es decir, no puede renunciar a la tesis de la relación universal entre la presencia de ciertas propiedades y la obtención de una consecuencia deóntica. Si lo hiciese, habría renunciado a la idea que lo define como universalista. Por este motivo he creído conveniente tomar en consideración sólo normas universales que establecen deberes superables, porque al hacerlo se pone de manifiesto el punto en el que se cifra la diferencia irreconciliable entre estas posturas. En resumen, de este modo se puede aislar el factor que se pretende analizar y, fundamentalmente, se pone de manifiesto que el problema de la universalidad de la relevancia de las normas (o del carácter invariable de las razones) es distinto del de la mayor o menor fuerza que ellas puedan tener. Por último, tal como ya he dicho, esta decisión se justifica también en que sólo el universalismo no absolutista puede admitir auténticos conflictos prácticos entre deberes, que para el universalismo absolutista no pueden tener lugar.

En resumen, el único modo de captar el sentido en que desde una posición particularista se puede hablar de normas o generalizaciones 
normativas es concediendo que tales normas son genuinamente derrotables y no son condicionales derrotables en el sentido de Alchourrón. A su vez, la única forma de expresar la idea de universalidad de la relevancia de las propiedades mencionadas en el antecedente de las normas sin superponer ni confundir esta idea con aquéllas (mucho más controvertidas, y en todo caso diversas) como la fuerza insuperable o concluyente de los deberes establecidos en su consecuente es concediendo que las normas pueden establecer deberes superables o pro tanto. Ninguno de estos dos requisitos se ve satisfecho en la propuesta de Caracciolo. En mi opinión, esto justifica el rechazo de la misma en este contexto, pero sobre todo explica por qué, aplicando su perspectiva a mi propuesta, resultan consecuencias paradójicas.

El trabajo de Caracciolo permite confirmar una idea explícitamente defendida en mi trabajo y según la cual no conviene enfocar la discusión universalismo-particularismo como un debate acerca de la forma lógica -estricta o derrotable- de las normas y del razonamiento práctico apoyado en normas. Si se es intransigente respecto de la noción de norma y se sostiene que ella hace siempre referencia a un condicional universal (enmascarado o desenmascarado), entonces el particularismo niega que haya normas válidas. Si en cambio se admite la posibilidad de normas "genuinamente derrotables", no reconducibles a condicionales universales, el particularista puede admitir que hay normas de ese tipo.

1.3. Dejando de lado estos problemas, el trabajo de Caracciolo invita a pensar sobre dos temas importantes. Si bien en un primer momento él aplica la idea de Alchourrón para criticar mi propuesta, luego concede que yo no estoy interpretando los condicionales derrotables a la manera de Alchourrón, puesto que mi objetivo es diseñar una noción de norma compatible con las tesis del particularismo. En esta perspectiva, las normas derrotables no serían otra cosa que un mero resumen o recordatorio de la relevancia que una cierta circunstancia puede tener en contextos definidos. Ahora bien, la pregunta es si estos enunciados -que en opinión de Caracciolo claramente 
tienen una función informativa y constituyen una generalización probabilísticapueden ser llamados en algún sentido "normas". Porque, según Caracciolo: si hay alguna distinción que hacer entre descripción y prescripción, la función de una generalización normativa tiene que consistir, al menos, en la determinación -y no en la descripción- de la corrección de una clase de acciones o de la relevancia de una clase de circunstancias.

En mi opinión, este aspecto hace explícita una consecuencia significativa del desacuerdo conceptual existente entre universalismo y particularismo. Como he ya mencionado, no hay una única interpretación standard de estos enunciados generales. Pero, en efecto, según el particularismo más extremo, ellos (i.e. las generalizaciones deónticas) son genuinamente derrotables y no tienen una función normativa, como pueden tenerla para el universalismo: no guían la acción, no constituyen razones, no determinan el status normativo de una acción. Inclusive, si se los identifica con meras generalizaciones estadísticas ni siquiera sirven para explicar por qué una acción tiene un status normativo. Sin embargo, si comprendo bien la propuesta, es justamente esto lo que el particularismo está tratando de decir, y si se mostrarse que estos enunciados deónticos generales tienen alguna función normativa se habría ofrecido un argumento en contra del particularismo. En otras palabras, un particularista opina que no tiene interés buscar principios generales o hacer generalizaciones normativas no porque rechace el interés o la importancia de la normatividad, de la justificación, o de las razones, sino justamente porque la normatividad, la justificación, y las razones no se encuentran allí, i.e. no se expresan a través de, ni tienen fundamento en, estos principios o generalizaciones. La justificación de nuestras acciones depende de que haya razones y estas son irremediablemente holistas, los enunciados acerca de la existencia de una razón son verdaderos o falsos dependiendo de cómo se conjuguen diversas propiedades en una determinada situación. Es decir, son contextuales y son normativos en la medida en que tienen contenido normativo, i.e. se refieren 
a razones que justifican acciones, pero no porque las constituyan o sean fuente de razones.

El particularismo está negando la invariabilidad, pero no la existencia de razones, ni su poder justificativo, es decir, en este sentido, no niega su normatividad. Su propuesta representa un desacuerdo acerca del concepto de normatividad porque decir que las razones son "normativas" significa que tienen capacidad para evaluar, justificar o criticar acciones individuales, es decir, establecer lo que se debe hacer en una ocasión particular, pero no significa que nos guíen hacia el futuro o que establezcan lo que se debe hacer en general. Este es un concepto posible de normatividad. Conforme a él, la fuente de la normatividad o capacidad justificativa de ciertas propiedades no debe buscarse en principios generales sino en el mundo, tal como se presenta en cada ocasión. Los principios generales, en todo caso, sólo podrían cumplir la prosaica función práctica de recordarnos, o ayudarnos a tener presente, las propiedades que pueden tener o que comúnmente tienen una función justificativa y normativa. Por ello, aunque el contenido de dichos principios es normativo, su función es meramente epistémica. La función justificativo-normativa la tienen las razones y no las generalizaciones que hacen referencia a ellas.

Retornando a la alternativa planteada por Caracciolo, respecto de si estas normas derrotables son autenticas generalizaciones normativas o meras generalizaciones empíricas, cabe responder que para un particularista se trata de generalizaciones acerca de hechos, pero estos hechos son normativos, i.e. son razones justificativas para la acción. Aunque resulte paradójico para quien niegue la posibilidad de la existencia y el conocimiento de hechos normativos y asuma una tajante separación entre descripción y prescripción, estas generalizaciones resultan a la vez informativas y normativas: tienen una función epistémica respecto de ciertos hechos normativos, i.e. existencia de razones justificativas.

1.4. Por último, cabe mencionar otra dificultad claramente señalada por Caracciolo respecto de la inestabilidad del contenido de las normas 
lógicamente derrotables. Tiene razón Caracciolo cuando afirma que la tesis de la identidad inestable de las normas DL es confusa. Si la identidad de una norma está fijada por su contenido, cuando éste cambia tenemos otra norma, y no la misma norma con contenido inestable. Entonces, si el contenido de la norma incluye un conjunto de condiciones implícitas que sólo se pueden identificar en la situación individual a la que se aplica, decir que las normas son inestables no significa que una única norma tiene un contenido variable según sea el contexto de aplicación, sino que existen tantas normas como ocasiones de aplicación. Esto conduce al problema subrayado por Caracciolo porque, entonces, el enunciado que expresa el contenido definitivo es el único que expresa una norma aplicable o no aplicable.

Pero entonces no existe una norma...antes de la operación de explicitación, cuya identidad pueda ser modificada o no modificada en el acto de su aplicación.

Caracciolo tiene razón: es incorrecto decir que la norma cambia en una ocasión individual, cuando en realidad el único contenido normativo aplicable se identifica en la ocasión individual. Ahora bien, según Caracciolo estas generalizaciones son "pseudo normas, que no pueden ser aplicadas ni dejadas de aplicar" y ello porque una norma "es aplicable o no aplicable sólo si su formulación concluye en la identificación de una norma no derrotable lógicamente”. Es decir, según Caracciolo, aplicar una norma significa aplicar la regla del modus ponens a un condicional que lo admite: a un condicional estricto.

Bajo esta definición, aplicar una norma implica reconocerle carácter de condicional universal, y ello equivale a admitir que los enunciados que expresan tales normas son reconstruibles como condicionales estrictos a partir de los cuales se puede deducir una conclusión. Un particularista sería auto-contradictorio si admitiese que las generalizaciones derrotables se pueden aplicar en este sentido. En mi opinión, desde un punto de vista lógicoformal, las normas genuinamente derrotables son sólo condicionales materiales que contingentemente expresan una condición contribuyente o 
suficiente para aplicar una consecuencia deóntica. Es decir, condicionales que contingentemente expresan una razón para la acción.

Recapitulando, estoy de acuerdo en que, tal como se propone por lo general, la distinción entre condicionales universales y condicionales derrotables sujetos a revisión se use para expresar la diferencia entre normas que establecen condiciones suficientes respecto de un deber final y normas que establecen condiciones contribuyentes para un deber final. Pero debería ser claro que éstas son dos formas de universalismo. Siendo así, queda abierta la cuestión de cómo expresar la posición de quien niega estos dos tipos de normas universales, es decir la posición según la cual los enunciados de la moral o del derecho no expresan condiciones suficientes ni contribuyentes para afirmar la existencia de un deber. La respuesta de Caracciolo a esta cuestión se ofrece al final de su trabajo, donde se insinúa que una posición de ese tipo está negando, o renunciando a, la propia idea de normatividad (de la moral o del derecho), visto que reduce los enunciados normativos (de la moral o del derecho) a meras generalizaciones empíricas.

La precisión de Caracciolo es importante, pero no creo que la conclusión sea que una posición de este tipo está reduciendo o cancelando la normatividad (del derecho o de la moral). Obviamente, si la idea de normatividad se concibe en términos universalistas, el particularista está renegando de ella; pero lo hace, justamente, porque propone una idea diferente de normatividad, no apoyada en principios universales sino en razones justificativas (propiedades relevantes) cuyo carácter es holista y contextual.

\section{2. ¿Podemos elegir entre particularismo y universalismo? Respuesta a Bruno Celano}

2.1. Las tesis que defiendo en mi trabajo pueden considerarse de carácter conceptual en la medida en que intentan precisar el modo en que el universalismo y el particularismo conciben las nociones de razón y 
razonamiento práctico. Ciertamente, el trabajo tiene también una pretensión reconstructiva. No me limito a constatar cuáles parecen ser las diversas nociones en juego, sino que sugiero cómo deben entenderse, o no entenderse, si se pretende que el debate entre universalismo y particularismo tenga sentido o exprese dos concepciones auténticamente alternativas de la racionalidad práctica. En este sentido, critico algunas formas de caracterizar las tesis del universalismo y del particularismo, y defiendo otras. En todo caso, es claro que en mi trabajo no tomo posición acerca de la bondad o de la conveniencia de asumir una u otra concepción filosófica. Es decir, no digo que una posición sea mejor o más adecuada, como tampoco digo que sean igualmente buenas o adecuadas. En este punto, creo que los comentarios de Celano presuponen un error de interpretación. Decir que dos concepciones son, ambas por igual, internamente consistentes -es decir, lógicamente posibles-y empíricamente viables, no es equivalente ni implica afirmar que ambas sean, por igual, plausibles o aptas para explicar algo, por ejemplo las razones jurídicas o morales. Siendo así, el esfuerzo de Celano por mostrar que ambas posiciones no están en una posición de igualdad para dar cuenta de lo que él considera "nuestra" concepción del razonamiento moral es admisible e interesante, pero no se opone en absoluto a las tesis sostenidas en mi trabajo. Esto es, que ambas concepciones son igualmente posibles (desde un punto de vista lógico y empírico). Celano intenta mostrar que sólo la concepción particularista explica adecuadamente nuestro razonamiento moral. En mi trabajo no he dicho nada que niegue esta tesis, pero, ante todo, no me he siquiera planteado el problema, quizás porque no estoy segura de que exista algo como un único tipo de razonamiento moral o "nuestro" razonamiento moral.

Más allá del acuerdo, o del desacuerdo, con las ideas de Celano, sus consideraciones indican que, en mi trabajo, no resulta claro el tipo de empresa que me propongo. Por ello, es importante hacer una precisión con respecto al objetivo del mismo y a la idea de "análisis" o "reconstrucción conceptual" que allí empleo.

Entiendo que no hay un único modo posible de concebir las razones, el razonamiento práctico, las normas, etc. Por ello, entiendo que no hay un 
único concepto posible de razón, razonamiento práctico, norma, etc. En mi trabajo he intentado analizar dos de estos modos, y lo he hecho porque en torno a ellos se desarrolla actualmente un amplio debate. Soy consciente de que al proponerse el análisis de un concepto los filósofos buscan identificar los rasgos esenciales del objeto que dicho concepto intenta capturar, independientemente de las diversas formas posibles de concebir tal objeto ${ }^{8}$. En efecto, creo que esto es lo que hacen universalistas y particularistas: discuten acerca de la naturaleza o los rasgos esenciales de nuestro razonamiento. Por este motivo, debería ser claro que mi trabajo no es parte en el debate universalismo-particularismo, no ofrece argumentos a favor o en contra de una posición, así como tampoco intenta identificar el concepto más plausible para explicar algunas de nuestras prácticas discursivas. Mi trabajo es una reflexión metateórica respecto del debate universalismoparticularismo en la que sostengo, entre otras cosas, que dicho debate: a) exhibe un desacuerdo conceptual respecto de la noción de razón'; b) que las dos propuestas en juego son lógicamente posibles y empíricamente factibles, es decir, de hecho cualquiera de ellas podría ser la articulación de nuestro concepto de razón; y c) que estas propuestas son mutuamente incompatibles. Ello significa que si nuestra concepción del razonamiento en el derecho penal, por dar un ejemplo, quedase correctamente explicada en un óptica universalista, entonces no sería adecuado usar la propuesta particularista para dar cuenta de nuestra concepción del razonamiento en dicho ámbito. En otras palabras, debería ser obvio mi fundamental acuerdo con Celano

${ }^{8}$ Conforme a J. Raz, (2004): "Concepts are how we conceive aspects of the world, and lie between words and their meanings, in which they are expressed, on the one side, and the nature of things to which they apply, on the other".

${ }^{9}$ Según cómo se caracterice la tarea de análisis conceptual se dirá, o bien que existe un desacuerdo acerca de las rasgos esenciales de un mismo concepto de razón (nuestro concepto de razón); o bien que existe un desacuerdo parcial respecto del concepto de razón, i.e. que ambas posturas conciben de modo parcialmente diverso las razones y, por ello, tienen conceptos sólo parcialmente coincidentes. Véanse, respectivamente, J. Raz (2004) y H. Brown (1999). 
respecto de que ambas reconstrucciones conceptuales, siendo incompatibles entre sí, no pueden ser igualmente adecuadas para capturar el modo en que funciona nuestro razonamiento en un especifico ámbito.

Probablemente una simple distinción disipa algunas de las dudas presentadas por Celano y ayuda a eliminar una posible confusión. Una cosa es identificar y analizar diversas formas posibles de concebir las razones y las normas. Esto es lo que he intentado hacer en mi trabajo. Una cosa diferente es preguntarse cuál de ellas capta o explica mejor el objeto al que se refieren. $\mathrm{O}$, dicho de otro modo, cuáles son las efectivas características de tal objeto. Esto último es lo que hace Celano en su comentario.

2.2. ¿El concepto universalista de razón es insatisfactorio, o imposible? Según Celano el modelo universalista, tal como lo analizo en mi trabajo, es "conceptualmente insatisfactorio" y una de las razones de esta insatisfactoriedad es que dicho modelo no capta adecuadamente nuestro modo ordinario de razonar. Es claro que esta tesis puede ser verdadera, sin que ello quite interés a la pregunta acerca de cuál es precisamente el concepto universalista para proponerlo, por ejemplo, como modelo de razonamiento en una situación ideal de dialogo, o para reconstruir lo que significa respetar las normas de una autoridad legítima ${ }^{10}$. Es decir, aun si fuese acertado que el modelo universalista no capta una forma de razonamiento moral ordinario, la implausibilidad de dicho modelo sería sólo relativa a ese objetivo preciso: la comprensión de una práctica argumentativa moral vigente u ordinaria.

Celano en ciertas partes de su trabajo concede que el razonamiento universalista puede aceptarse con carácter circunscrito. Al respecto, cabe observar que el hecho de que la concepción universalista se aplique a un ámbito circunscrito no quita que dicho ámbito pueda ser de la mayor importancia. Pero, sobre todo, no quita que sea auténticamente universalista,

\footnotetext{
${ }^{10}$ Sólo por mencionar dos ejemplos, la idea de razón pública de J. Rawls, o de razón excluyente de J. Raz conforman tipos de razonamientos universalistas.
} 
que es lo único que está en cuestión en este contexto. Sin embargo, y no obstante esta aparente concesión, Celano afirma que nuestro razonamiento universalista no es auténticamente tal, en realidad, no está sólo circunscrito sino que es precario y provisorio porque en cualquier momento podríamos volver a nuestra forma de razonamiento ordinaria, es decir, particularista. Consideraciones de este último tipo podrían interpretarse como tendientes a mostrar que la concepción universalista es empíricamente imposible porque nuestra conformación psicológica impide que asumamos compromisos estables, o algo similar. Sin embargo, ésta no puede ser la tesis de Celano, puesto que admite que no hay problemas lógicos ni empíricos en la aplicación de la concepción universalista ${ }^{11}$. Ahora bien, aunque en línea de principio el razonamiento universalista es posible, según Celano presupone la verdad de una tesis mal formada y, consecuentemente, no ofrece una genuina opción para la reconstrucción de nuestro razonamiento. La pregunta sobre cuál de los dos modelos en cuestión reconstruye adecuadamente nuestro razonamiento moral tiene en realidad una única respuesta factible porque la otra tiene un defecto irremediable.

Probablemente Celano tiene razón cuando afirma que el modelo particularista capta mejor nuestro razonamiento moral ordinario. Sin embargo, no creo que el único objetivo teórico interesante sea reconstruir el razonamiento moral ordinario ni, sobre todo, que la satisfacción de este especifico objetivo teórico deba ser tomada como único criterio de adecuación para afirmar la superioridad absoluta de un modelo sobre el otro. A mi entender, la superioridad de uno u otro modelo no puede ser establecida en general, como pretende Celano, sino con relación a específicos objetivos teóricos. Además, en todo caso, la superioridad o la preferencia de uno u otro modelo no se apoya en que uno de ellos padece defectos insalvables sino que depende de una cuestión contingente: de las específicas características del tipo razonamiento que se quiere explicar.

${ }^{11}$ Véase B. Celano (2005) en este mismo número. 
Tal como he ya dejado entrever, no me es claro si la conclusión que debemos extraer del trabajo de Celano es la imposibilidad del concepto universalista de razón o la implausibilidad de dicho modelo. Sí es claro, en cambio, que para Celano no hay posibilidad de optar o elegir entre dos modelos, al menos por dos motivos. En primer lugar, porque él presupone que el objetivo teórico es uno solo: explicar nuestra manera ordinaria de argumentar moralmente. En segundo lugar, porque, bien vistas las cosas, no hay dos modelos viables entre los cuales elegir. Uno de ellos, el universalismo, padece un defecto insalvable; por este motivo su implementación es siempre precaria, o meramente aparente. En otras palabras, el modelo universalista es desechable, salvo que -como se sugiere después de las apreciaciones críticas- se reinterprete en la perspectiva que propone el autor.

En la perspectiva de Celano, nuestro razonamiento es claramente particularista y la única distinción que podemos establecer se apoya en la mayor o menor disposición a modificar o rever nuestras generalizaciones prescriptivas. Si estamos totalmente abiertos y dispuestos a desatrincherarlas somos decididamente particularistas; si, en cambio, somos reacios a hacerlo y exigimos garantías especialmente fuertes para ello, somos universalistas. De este modo, la distinción universalismo-particularismo deviene una cuestión de grado. En sentido estricto, no hay dos modelos diferentes de razonamiento sino uno solo, que se aplica con mayor o menor rigor. Un universalista es un particularista sobrio, que no está dispuesto a tratar las generalizaciones como absolutamente transparentes, pero que siempre se reserva la posibilidad de revisar su contenido a la luz del caso concreto. En mi trabajo, no he intentado negar la posibilidad de establecer una diferencia gradual de este tipo. Ciertamente, una generalización puede ser considerada más o menos opaca. Pero, como acabo de decir, esta interpretación niega que haya dos modelos cualitativamente distintos de razonamiento práctico y, más concretamente, niega que haya razones invariablemente relevantes. Si la aceptamos, es claro que la discusión universalismo-particularismo deja de ser una discusión conceptual. Desde este punto de vista, defender una u otra posición significa 
defender actitudes más o menos abiertas a la revisión de las generalizaciones, bajo la presuposición límite de que no cabe siquiera concebir aquello que se apoya en una tesis irremediablemente defectuosa e inadmisible: la invariabilidad de la relevancia de las razones. Es interesante observar que en la interpretación alternativa que ofrece Celano, la posición universalista no sólo no es incompatible ni excluyente respecto del particularismo, sino que lo presupone y constituye una forma muy atenuada del mismo. Vistas así las cosas, no sólo pierde interés oponer el particularismo al universalismo sino que sería un error hacerlo. A mi modo de ver, esta lectura no permite captar el aspecto central del debate universalismo-particularismo: el desacuerdo acerca de la variabilidad-invariabilidad de la relevancia de las razones, y visto que sentencia la necesidad de abandonar la tesis universalista -por apoyarse en una idea mal formada-, esta lectura debe ser rechazada por todo aquel que quiera conservar un espacio lógico para dicha tesis.

2.3. Consecuentemente, una cuestión central en esta discusión es establecer si un modelo de razonamiento universalista, cualitativamente diverso del particularista, es efectivamente factible.

Según Celano, el modelo universalista implica la idea de "una tesis de relevancia última". Es decir, implica que podamos acceder a una especificación previa y exhaustiva de las propiedades éticamente relevantes de las acciones ${ }^{12}$. El lenguaje escogido por Celano, a mi juicio, constituye un modo alternativo para expresar que el universalismo supone un conjunto finito de normas universales válidas ${ }^{13}$. Este conjunto de normas válidas fija un conjunto de propiedades invariablemente relevantes. Todo el trabajo de Celano está dirigido a mostrar que esta tesis no puede ser aceptada. Si su

\footnotetext{
${ }^{12}$ Véase B. Celano (2005) en este mismo volumen.

${ }^{13}$ Recuérdese que en mi trabajo, siguiendo en este aspecto a Shafer-Landau, asumo que la correlación universal entre un conjunto de condiciones antecedentes y un consecuente deóntico, i.e. la idea de norma universal, nada dice acerca del status metaético de dichas normas.
} 
argumento es exitoso, el ideal universalista se debe abandonar porque se apoya en una tesis mal formada. Me referiré a esta idea como "la tesis del carácter mal formado" (que se refiere a la tesis de relevancia última o, lo que es lo mismo, a la tesis de la existencia de un conjunto último de normas).

Celano utiliza ambigua e imprecisamente tanto la expresión "tesis de relevancia última" como el predicado "mal formada". En efecto, según he dicho antes, no es claro si el carácter mal formado de la tesis de relevancia última indica que dicha tesis es imposible, o simplemente implausible en relación con un objetivo dado, que en opinión del autor es de importancia fundamental. En todo caso, creo que es importante precisar qué es lo que el universalismo presupone y que según Celano padece este defecto insalvable: la tesis de relevancia última, y por qué a los ojos de Celano constituye una tesis mal formada.

La noción de "tesis de relevancia última" merece ser precisada al menos en tres sentidos diferentes. La expresión "última" es ambigua: puede hacer referencia al carácter concluyente o final de un conjunto de propiedades que constituyen la tesis de relevancia, a su carácter completo, o a su carácter definitivo, estable o no maleable ${ }^{14}$. La tesis de relevancia presupuesta por el universalismo, y negada por el particularismo, es última en el tercer sentido. Esta precisión es importante porque el particularismo no puede criticar la admisión de una tesis de relevancia última en el primer sentido, es decir, la existencia de un conjunto de propiedades relevantes que permiten determinar en modo final o concluyente la calificación deóntica de una acción. Si negase esto sería una posición escéptica. Asimismo, ninguna de las dos posiciones tiene que comprometerse con la defensa de un sistema completo de propiedades relevantes. En cambio, lo que sí niega el particularismo, y en cambio presupone el universalismo, es que la relevancia de dicho conjunto de propiedades sea última en el sentido de estable o no maleable.

${ }^{14}$ Volveré sobre este tema mas adelante en mi respuesta a Moreso. 
Por otra parte, aunque pueda parecer obvio o trivial, es conveniente subrayar explícitamente que el carácter último, definitivo o estable, de la tesis de relevancia es justamente un predicado que hace referencia a la tesis de relevancia y no al conocimiento o a las creencias que podamos tener sobre ella. Esto es tanto como recordar que la idea definitoria del universalismo es ontológica, i.e. la existencia de un conjunto de propiedades de relevancia invariable, y no epistemológica, es decir, si bien debe ofrecer algún modo de acceso al conocimiento de estas propiedades, no se compromete ni se define por una tesis relativa al modo en que ese acceso o conocimiento se produce. Por ello, en ningún caso la idea de tesis de relevancia última debe interpretarse como haciendo referencia a la posibilidad de acceso u obtención de un conjunto estable, definitivo o inderrotable de creencias. Esta interpretación conduciría a conclusiones absurdas y en ningún sentido está implícita en la propuesta universalista. Una tesis que sostuviese que nuestras creencias, por el hecho de estar justificadas, son definitivas, estables o inmodificables sería dogmática e irracional ${ }^{15}$.

Por último, cabe mencionar que una "tesis" de relevancia puede proponerse con fines descriptivos o prescriptivos. De hecho, no es claro en cuál de estos sentidos la interpreta Celano. El universalismo, ya sea en el ámbito moral o jurídico, afirma que es posible contar con una tesis última de relevancia normativa, es decir, con un conjunto de propiedades que deben ser tenidas en cuenta al momento de responder a la pregunta práctica acerca de qué predicados evaluativos o deónticos podemos aplicar a una determinada situación. El universalismo, en cambio, no necesita presuponer la existencia de una tesis de relevancia última descriptiva, es decir, un conjunto último de propiedades que indican cómo se identifica o describe, con verdad, una acción o situación. Juzgo que esta distinción es fundamental ya que si bien el universalismo presupone que haya algún modo de controlar

${ }^{15}$ Al respecto, J.C. Bayón en J.C. Bayón y J. Rodríguez (2003), p. 282. 
la corrección, verdad, o adecuación de la identificación y descripción de acciones, no requiere que haya un conjunto último (estable) de propiedades naturales a tener en cuenta en la identificación de una acción ${ }^{16}$. Por ello, tal como he dicho antes, la existencia de una "tesis de relevancia última" implica la existencia de un conjunto finito de normas universales. En otras palabras, el universalismo presupone la existencia de un conjunto último de normas universales o inderrotables que establecen o confieren relevancia normativa estable a un conjunto finito de propiedades naturales (en la medida en que correlacionan invariablemente la presencia de dichas propiedades con la obtención de consecuencias deónticas).

Hasta aquí, lo que el universalismo presupone. Ahora cabe establecer qué dificultades presenta esta tesis o cuáles son los argumentos que se esgrimen en contra de la misma. La razón fundamental para afirmar el carácter mal formado de la tesis de relevancia última es que, según Celano, las propiedades potencialmente relevantes para la descripción de una acción son indefinidas. Una acción puede ser descripta en una cantidad no especificable de modos posibles. No es dable indicar por anticipado todas las características que pueden resultar pertinentes para la descripción de una acción, y esto significa que no es posible una especificación previa de los casos posibles éticamente relevantes.

Ahora bien, a pesar de que Celano argumenta convincentemente a favor del carácter indefinido de las propiedades que pueden ser tenidas en cuenta para describir una acción, creo que tal argumento nada dice en

\footnotetext{
${ }^{16}$ Por supuesto si cualquier descripción fuese admisible se podría siempre manipular la descripción de la acción en modo tal de incluirla en o excluirla del ámbito de aplicación de una norma. El universalismo no presupone que haya una única descripción verdadera pero sí un criterio de control del discurso referido a las acciones. En todo caso, del hecho de que un mismo comportamiento pueda ser descripto en indefinidas formas posibles no se sigue que todas ellas sean aceptables o admisibles. En el ámbito jurídico, por ejemplo, sólo se consideran descripciones aceptables aquellas que satisfacen ciertos requisitos, tales como contar con específicas pruebas a su favor.
} 
contra de la posibilidad de una tesis de relevancia normativa última ${ }^{17} \mathrm{o}$, en otros términos, acerca de la posibilidad de fijar un conjunto último de normas válidas que especifican razones invariablemente relevantes.

Lo que Celano está llamando una tesis de relevancia última es aquello que propone toda teoría de ética normativa. ¿En qué sentido está mal formada, por ejemplo, la tesis utilitarista según la cual la única propiedad invariablemente relevante para evaluar las acciones es la utilidad? ¿Qué importancia tiene, a este fin, advertir que cualquier propiedad es potencialmente relevante? Una teoría de ética normativa es la propuesta, y justificación, de un conjunto finito -i.e. una selección- de principios normativos. Al ofrecer una base para guiar y evaluar acciones una teoría de este tipo lo que hace es delimitar y justificar un conjunto de propiedades de relevancia última o estable. Si se limitase a decir que cualquier propiedad es potencialmente relevante, o que las propiedades justificadas como relevantes, en realidad, pueden no serlo, no estaría ofreciendo ninguna guía o criterio para evaluar el comportamiento. Sin una teoría que opere una selección de propiedades relevantes es imposible evaluar una acción. Si esta conclusión se acepta, el particularista se encuentra en una posición difícil. Visto que no es una posición escéptica, y por lo tanto precisa, en algún sentido del término, de una teoría normativa (i.e. de una selección justificada de propiedades relevantes para evaluar las conductas) tendrá que aceptar, o bien una teoría estable, es decir, lo que propone el universalismo, o bien una teoría ad hoc para cada ocasión. Esta alternativa es ineludible: un particularista no puede limitarse a afirmar que cualquier propiedad es potencialmente relevante, debe mostrar cómo se llega a la teoría que delimita las propiedades efectivamente relevantes para juzgar

\footnotetext{
${ }^{17}$ En rigor, tampoco dice nada con relación a la posibilidad de una tesis última de relevancia descriptiva. También para describir una acción es indispensable contar con una teoría que delimite, entre las indefinidas propiedades potencialmente relevantes, aquellas que han de contar como efectivamente relevantes. La descripción de una acción puede juzgarse correcta y/o completa sólo desde del punto de vista de una teoría que opera este tipo de delimitación.
} 
una acción, de lo contrario no podría emitir algún juicio deóntico o evaluativo y caería en el escepticismo. Consecuentemente, el argumento particularista debe ser completado. En efecto, las propiedades potencialmente relevantes son indefinidas, pero existe un conjunto definido de propiedades efectivamente relevantes, coherentemente concebible y accesible, que queda fijado por el modo en que las propiedades se conjugan en cada situación particular. Es decir, el particularismo supone una recomendación de abandonar toda teoría universal de ética normativa, pero presupone la posibilidad de justificar una teoría ad hoc para cada situación.

No discutiré aquí la plausibilidad de una propuesta de este tipo.

Expongo estas ideas sólo para poner de relieve que la tesis subrayada por Celano, según la cual cualquier propiedad puede devenir relevante o, en otros términos, que las propiedades potencialmente relevantes son indefinidas, es una tesis en sí misma inocua respecto del universalismo. Cualquier posición sobre las razones para la acción -sea universalista o particularista- puede admitir que existe un conjunto indefinido de propiedades potencialmente relevantes, pero justamente por ello, en la medida en que no sea escéptica, deberá delimitar y justificar una tesis de relevancia normativa, y comprometerse con ella; de lo contrario no permitiría justificar ninguna acción o decisión, i.e. llevaría a consecuencias escépticas. Es claro que para una concepción particularista esta tesis de relevancia normativa no tiene carácter último (en el sentido de estable o no maleable). Pero, en cualquier caso, es una tesis de relevancia normativa, es decir, una selección o conjunto finito de propiedades relevantes que permiten justificar aquello que se debe hacer en un caso individual. Desde este punto de vista, tanto una posición universalista como una particularista están sometidas a la exigencia de justificar un conjunto de propiedades que deben efectivamente ser aceptadas como relevantes. La advertencia de que esta selección se debe operar a partir de un conjunto indefinido de propiedades potencialmente relevantes no es un argumento en contra del universalismo. En todo caso, si se interpreta como una dificultad, es una dificultad que tiene que enfrentar cualquier teoría no escéptica y no sólo el universalismo. 
Sobre esta base puede afirmarse que el argumento apoyado en el carácter indefinido de las propiedades potencialmente relevantes de cada caso individual, al límite, puede tomarse como una reformulación de la ya conocida dificultad señalada por Schauer según la cual comprometerse con un conjunto invariable de propiedades relevantes presenta siempre las dificultades de la sub- y sobre inclusividad frente a una situación individual. Sin embargo, si la crítica es ésta, y lo que se está subrayando es que una teoría ad hoc (elaborada para el caso individual) está en mejores condiciones para captar propiedades efectivamente relevantes no previstas en la tesis de relevancia última de una teoría universalista, entonces no es suficiente para probar el carácter "mal formado" de la tesis de relevancia última. Cuanto más, podría ser la base para mostrar el carácter no óptimo de los resultados esperables a partir de la aplicación de una propuesta universalista. Sin embargo, a este punto cabe recordar que cualquier revisión o crítica a una tesis de relevancia debe apoyarse, no en un conjunto indefinido de propiedades potencialmente relevantes, sino en una teoría alternativa, es decir, en un conjunto definido, ciertamente contrastante con respecto al primero, pero igualmente susceptible de error. Ello es así porque una vez seleccionado un conjunto de propiedades relevantes, sea que se considere invariable, como propone el universalismo, o sólo relativo a un caso individual, como propone el particularismo, existe siempre la posibilidad de error. Ninguna de las dos estrategias puede garantizar un resultado óptimo.

Si bien no es del todo claro qué tipo de defecto se señala al afirmar el carácter mal formado de una tesis de relevancia última o de un conjunto último de normas universales, al menos las siguientes interpretaciones pueden considerarse injustificadas $\mathrm{y}$, por ese motivo, provisoriamente deben rechazarse. En primer lugar no indica un defecto lógico y si se le diese una lectura de ese tipo, la tesis del carácter mal formado no habría sido probada, visto que no se ha producido ningún argumento tendiente a mostrar la existencia de una contradicción interna a la tesis universalista. En segundo lugar, descarto que el argumento de Celano haga referencia a una 
imposibilidad metafísica, si bien el presupuesto en discusión, y al que se dirige la crítica, tiene carácter metafísico ${ }^{18}$. Si recibiese esta lectura, la tesis del carácter mal formado sería tan indemostrable como aquella a la que se intenta contraponer pero, en todo caso, Celano no ha querido ofrecer un argumento trascendental ni plantear una discusión metafísica. Lo más razonable parecería ser una lectura evaluativa, según la cual el defecto señalado por Celano sería un modo alternativo de expresar el carácter deficitario o sub óptimo de las decisiones que aceptan y se apoyan en una tesis de relevancia última ${ }^{19}$. En este caso, hablar del carácter mal formado parece desproporcionado. Si bien es cierto que un modelo decisional que asume una tesis de relevancia normativa última o estable puede no garantizar en toda ocasión un resultado óptimo -óptimo, a la luz de otra tesis de relevancia construida ad hoc para el caso individual-, parece una exageración llamarle por eso "mal formado". Sobre todo porque una crítica expresada en estos términos insinúa que la posición que padece tal defecto debe ser abandonada, con lo cual, indirectamente, constituiría un argumento a favor de la posición competitiva. Esto último sería claramente un error. El carácter deficitario o sub-óptimo de una teoría universalista no excluye que al particularismo pueda dirigirse una recriminación análoga ${ }^{20}$. También el modelo decisional particularista, que se compromete necesariamente con una tesis de relevancia normativa ad hoc, debe admitir la posibilidad de llevar a resultados no óptimos, a la luz de una teoría alternativa o una evaluación ex post facto, a través de la cual se podrían identificar propiedades efectivamente relevantes,

${ }^{18}$ En el mismo sentido, tal como señala J. Dancy, también la tesis particularista debe ser entendida como una tesis metafísica. Cfr. J. Dancy (2004), p.140.

${ }^{19}$ En esta lectura, el reproche que se estaría dirigiendo a la tesis de relevancia última sería idéntico al que discute Schauer en referencia a la suboptimalidad de las reglas, con la única diferencia que la divergencia extensional que produce una experiencia recalcitrante de sobreo sub-inclusividad no consiste en una discordancia entre la tesis de relevancia última y una justificación subyacente a la misma, sino en un desajuste entre la tesis de relevancia última y una justificación ocasional o ad hoc, de tipo particularista.

${ }^{20}$ Cabe recordar los dos tipos de error a los que se refiere F. Schauer (1991), pp. 149-155. 
que se desconocían o se subestimaron en el momento de la decisión. Y a ello debería sumarse, si tomamos en consideración los argumentos de Schauer, que al menos por cuanto se refiere al derecho no siempre es claro que debamos confiar más en la sensibilidad, y en la tesis de relevancia normativa ad hoc que un decisor elabora para el caso individual, que en la sensibilidad y en la tesis de relevancia normativa estable de un sistema de normas universales. Por último, cabe mencionar la posibilidad de que el "carácter mal formado" sea una dificultad de tipo epistémico. La crítica de Celano puede ser leída en este sentido porque este autor no parece interesado en distinguir los problemas que puede presentar la idea de tesis de relevancia última de aquellos relativos a la posibilidad de acceso a dicha tesis. Como ya he mencionado, si bien el universalismo presupone esta posibilidad de acceso o conocimiento moral, sería un error trasladar el carácter último, invariable y estable, que para el universalismo tiene la tesis de relevancia, al conjunto de creencias morales o a las diversas tentativas de acceso a la tesis de relevancia última. Consecuentemente, si la afirmación del carácter mal formado de una tesis de relevancia última intenta señalar que no es posible presuponer la posibilidad de acceso último o inderrotable, o un conjunto de creencias estables o invariables sobre aquello que es moralmente relevante, estaría señalando algo sensato; sin embargo, no estaría presentando una crítica al universalismo porque estas no son tesis presupuestas por el universalismo.

2.4. ¿Es posible distinguir una norma de su formulación normativa? Celano sostiene abiertamente que en su opinión no hay objetos tales como las normas universales ${ }^{21}$. En ese sentido es comprensible que, desde su perspectiva escéptica con relación a la existencia de normas universales, carezca de sentido la distinción entre el supuesto objeto de conocimiento (un conjunto de normas o una tesis de relevancia última) y las creencias o formulaciones subjetivas que (aparentemente) a él se refieren. En efecto,

${ }^{21}$ Cfr. B. Celano (2005) en este mismo número. 
en este caso, dicha distinción es imposible puesto que el objeto de conocimiento ( si lo hay) no es otro que el conjunto de creencias y formulaciones de los sujetos. Sólo si reconocemos algún grado de objetividad a algo, podremos, en la misma medida, distinguirlo de las formulaciones y creencias a él referidas. Considero que esta afirmación es válida respecto de cualquier tipo de objeto de conocimiento ¿Por qué no debería serlo con relación a un conjunto de normas o a una tesis de relevancia? Esta distinción no requiere que el objeto de conocimiento (el conjunto de las normas o la tesis de relevancia) sea totalmente independiente de la las actitudes y creencias de los agentes $^{22}$. Por ejemplo, es ampliamente admitido que, desde una perspectiva positivista, la existencia de normas depende de una fuente social, es decir, es relativa a una práctica de comportamientos, actitudes y creencias de un grupo de personas. No obstante ello, aun en dicha perspectiva, la existencia de una norma se puede distinguir de las creencias y actitudes de cada agente individualmente considerado.

La afirmación de Celano según la cual es imposible distinguir entre normas y formulaciones es interna a una perspectiva que niega la "objetividad" de las normas, es decir, a una posición que parte de una premisa escéptica acerca de las normas, y se justifica a partir de tal presuposición. Pero, sin embargo, es justamente éste el punto que está en cuestión. El universalismo sostiene la tesis metafísica exactamente contraria al escepticismo: defiende la existencia de un conjunto de normas universales distinguibles de nuestras formulaciones y creencias acerca de las mismas.

En pocas palabras, la tesis de Celano acerca de la indistinguibilidad de las normas de sus formulaciones presupone aquello que se debe demostrar: que hay razones para rechazar la tesis universalista acerca de la existencia de normas, pero no ofrece un argumento para dicho rechazo o para atribuirle un carácter mal formado.

\footnotetext{
${ }^{22}$ No me detendré sobre este punto. La existencia de un objeto como el derecho, por ejemplo, no necesita ser independiente de toda actitud humana para que se puedan distinguir entre proposiciones objetivamente verdaderas y falsas con relación al mismo. Al respecto, véase por ejemplo J. Raz (2001), pp. 194-233.
} 
Celano asume la tesis escéptica con relación a la existencia de normas en sentido estricto porque cree haber demostrado el carácter mal formado de la tesis universalista, es decir, el carácter mal formado de la propuesta de un conjunto de normas universales y de razones invariables. A sostén de esta idea se esgrime un último argumento de carácter semántico. A tenor del mismo, la idea de norma universal requiere significados estables y no existe una teoría que fije de manera invariable el significado de las palabras. Al respecto, sólo un breve comentario. Celano no intenta sostener la tesis de la radical indeterminación de los significados que, en todo caso, afectaría por igual a una teoría de corte universalista o particularista respecto de las razones. Lo que este autor señala es que no es plausible pensar que el lenguaje tiene significado estable o invariable, ni existe una teoría del significado que avale tal posibilidad. Creo que se puede estar totalmente de acuerdo con Celano respecto de la inexistencia de un conjunto finito de reglas que determinan el significado de las palabras, y sin embargo seguir admitiendo un conjunto finito de normas que determine el contenido de las razones jurídicas o morales. Una teoría universalista de las razones justificativas no depende ni se apoya en una teoría del significado o sobre la interpretación de textos. Es decir, aun admitiendo que no existe y que no tiene sentido defender una teoría que fije el significado de las palabras de un lenguaje, puede ser posible y plausible admitir una teoría que fija qué circunstancias o propiedades tienen relevancia jurídica o moral. En rigor, como he dicho antes, tanto el universalismo como el particularismo exigen una teoría de este tipo para poder tomar decisiones justificadas sobre la base de razones. En este punto, las consideraciones de Celano me permiten aclarar algo que quizás he expresado confusamente en mi trabajo original. El universalismo presupone la posibilidad de conocer normas o contenidos normativos que, si bien pueden ser dependientes de un grupo social, no son relativos ni son una función del caso individual. Por este motivo he sostenido que, en al ámbito jurídico, aquellas posiciones según las cuales el decisorintérprete es el verdadero creador de las normas jurídicas, frustran el ideal 
universalista. Este tipo de posiciones no propone una teoría semántica sino una teoría jurídica. Tal teoría, si bien admite que el derecho es un conjunto de normas generales, no es universalista respecto de las razones que ofrece el derecho. Ello es así porque las normas generales que constituyen el derecho son aquellas que los jueces identifican en las ocasiones individuales de decisión. Un modelo de toma de decisión que en línea de principio se basa en la aplicación de normas o principios generales, pero que admite la maleabilidad del contenido de tales normas o principios a la luz del caso individual es materialmente equivalente a un modelo de toma de decisión particularista ${ }^{23}$. Es decir, este tipo de teoría del derecho, que creo es adscribible a un autor como Alf Ross ${ }^{24}$, aun cuando acepta que el derecho es un conjunto de normas generales, paradójicamente, es incompatible con una posición universalista respecto de las razones que ofrece el derecho y lo es, no en

${ }^{23}$ Cfr. F.Schauer (1991), p. 84.

${ }^{24}$ En mi trabajo cito al respecto las propuestas de G. Tarello y R. Guastini. Sin embargo, según Guastini, su teoría no sería escéptica en este sentido porque no admite que la norma general quede fijada o dependa del caso particular. Para poder sostener esta idea se hace necesario distinguir entre interpretación en abstracto e interpretación en concreto. En el primer caso, los decisores identifican (conocen, o deciden) el contenido de la norma en abstracto, en el segundo caso, los decisores, si bien no alteran la identidad de la norma en abstracto, pueden modificar su ámbito de aplicación en relación al caso individual (mediante específicas técnicas de interpretación como la disociación, la analogía, la interpretación extensiva o evolutiva, etc.). Dicho metafóricamente, en esta perspectiva la norma en abstracto no ejerce presión normativa ni es opaca frente a las propiedades que se consideran relevantes en el caso individual. Si la norma resultante de la interpretación en abstracto no toma en consideración dichas propiedades, el decisor no puede modificarla, pero puede adaptarla. Independientemente del nombre que reciba el contenido resultante de la interpretación en concreto (¿norma concreta, o norma aplicable?) es evidente que la norma en abstracto -por las mismas razones en virtud de las cuales se admite, o es necesaria, la interpretación en concreto- no es vinculante en el caso individual. Las definiciones aportadas permiten afirmar que la decisión se toma sobre la base de una norma general cuya identidad no depende del caso individual. Sin embargo, dicha decisión se justifica, no en las propiedades consideradas relevantes por las normas en abstracto, sino en las propiedades que el decisor considera relevantes en el caso individual. A mi juicio es exactamente éste el tipo de propuestas que según Schauer, si bien admiten normas generales, configuran un modelo de toma de decisión materialmente equivalente al propuesto por el particularismo. Cfr. R. Guastini (2001), pp. 147-152. 
virtud del escepticismo interpretativo que suscribe, sino en virtud de la concepción del derecho que defiende.

2.5. Una importante vía argumental seguida por Celano para mostrar la superioridad del particularismo reside en su crítica a la posibilidad de distinguir entre un universalismo que admite razones superables o pro tanto (el que yo he caracterizado en mi trabajo) y un universalismo que sólo admite razones insuperables, finales o concluyentes (absolutismo). Según Celano, para ser inteligible, el universalismo debe sostener que las razones no sólo son universales sino insuperables o concluyentes. En su opinión, un universalismo que admita que las razones son pro tanto es indiscernible del particularismo. Como se ve, en este caso, la crítica no se dirige al universalismo, en general, sino específicamente a un universalismo no absolutista, como el que he considerado en mi trabajo

$¿$ Hay realmente una diferencia apreciable entre las razones universales pro tanto y las razones en sentido particularista, o son dos formulaciones diferentes de la misma idea? A mi juicio, cancelar o no apreciar la diferencia entre estas dos ideas presupone haber cancelado, o no apreciado, la diferencia entre universalismo y particularismo. Calculo que justamente a esto apuntan los argumentos de Celano, a cancelar una distinción categorial entre dos tipos de razonamientos por considerar que existe un único modo (particularista) de razonar, más o menos abierto a la revisión de las generalizaciones que sirven de apoyo. Sin embargo, ello supone no apreciar que existe una auténtica distinción entre defender que las razones tienen carácter invariable, por una parte, y que tienen carácter holista y contextual, por otra. O, lo que es lo mismo, ello supone no advertir que tal diferencia nada tiene que ver con el peso superable o insuperable, o el carácter pro tanto o concluyente de las razones, sino con la universalidad de su relevancia. Si no se es sensible a la diferencia que existe entre defender y rechazar la tesis de la universalidad de la relevancia no se puede apreciar la diferencia entre razones pro tanto y razones particularistas, puesto que no se es sensible a la única característica que permite diferenciarlas. 
Tal como afirma Celano, por cuanto se refiere al resultado de una decisión concreta, las dos formas de concebir las razones pueden conducir a idéntica solución. Una vez identificadas las razones, sobre todo si el razonamiento práctico en el que ellas entran en juego (una ponderación o balance de razones) se configura en una perspectiva cuantitativa, como una función en la que las razones se suman y restan como "pesas" que determinan un resultado, la diferencia puede ser realmente evanescente ${ }^{25}$. En esta óptica, que una consideración tenga poquísimo peso o no tenga ninguno es, "desde un punto de vista práctico", irrelevante. En esta expresión, "desde un punto de vista práctico" significa "desde el punto de vista del resultado final", es decir, de la acción que en definitiva se justifica o se rechaza. Sin embargo, y tal como he intentado exponer en mi trabajo, aun cuando, desde la perspectiva del resultado, una decisión tomada conforme a un modelo particularista podría ser idéntica a otra que se compromete con el universalismo, de ello no se sigue que no haya una diferencia práctica apreciable entre ambas propuestas. Obviamente, dicha diferencia no radica en los resultados concretos que cada uno de estos tipos de razones pueden autorizar sino en el compromiso con concepciones contrapuestas acerca de cómo llegamos a identificar tales razones, cuál es su alcance y cuál el tipo de razonamiento práctico que ellas imponen para considerar justificado un resultado. El universalismo está necesariamente conectado con la idea de norma universal, a su vez el modelo de razonamiento apoyado en normas está comúnmente asociado a las ideas de previsibilidad, igualdad formal, así como también a una específica forma de distribución del poder, etc. A mi juicio, estos compromisos tienen fuerte relevancia "desde un punto de vista práctico", donde ello no significa que garanticen específicos resultados. Como sabemos la diferencia entre las dos posiciones es de tipo metaético y no de ética normativa. Admitida la posibilidad que posiciones universalistas y particularistas permitan justificar

${ }^{25}$ Véase S. Kagan (1988), pp. 5-31. 
idénticos resultados, se puede decir que la diferencia radica en que, para el universalismo, dicho resultado o decisión es justo en la medida en que con él se honran las razones correctas, i.e. universalmente justificadas, de relevancia invariable, que nos deben guiar en la identificación del resultado. En contraste, para el particularismo, las razones correctas son aquellas que permiten obtener el resultado o la decisión justos en una ocasión particular y son las características del mismo las que nos deben guiar en la identificación de las razones que se deben honrar.

El carácter fundamental de la diferencia entre admitir la posibilidad de justificar propiedades con relevancia invariable (aunque superable y por ello pro tanto) o, en cambio, razones que sólo existen en relación a un caso particular deviene especialmente clara en el ámbito jurídico. La mayor parte de los sistemas jurídicos contemporáneos no sólo asumen implícitamente un compromiso con la idea de universalidad de la relevancia, sino que en modo expreso la incorporan como el contenido de normas positivas que establecen el principio de igualdad ante la ley.

En un sentido estricto, si el derecho se define como un conjunto de normas universales, la incorporación de un principio específico de universalidad de la relevancia o de igualdad formal debería considerarse superflua. Ello es así porque lo único que dice un principio de ese tipo es que las normas universales válidas deben ser tratadas como normas universales válidas, i.e. como ofreciendo razones invariablemente relevantes. En cualquier caso, principios como el de igualdad formal ante la ley ofrecen cuanto menos una prueba de que la diferencia entre decisiones vinculadas y no vinculadas a principios preexistentes (i.e. decisiones que se comprometen con la relevancia invariable de ciertas propiedades y decisiones que, aun produciendo resultados análogos, no lo hacen) no parece ser irrelevante en la organización jurídica de los estados de derecho. En este sentido, puede afirmarse que la idea de estado de derecho asume el carácter universal de las razones jurídicas, es decir, supone que el derecho ofrece un conjunto limitado de normas o principios que, si bien por sí mismos no especifican un 
resultado, establecen razones cuya consideración es vinculante para los decisores, y que deben ser honradas en la decisión final. Esta idea no se concilia con la tesis del particularismo. Es decir, puede afirmarse que la concepción particularista no explica el modelo de decisión presupuesto en nuestra concepción del estado de derecho, mientras sí lo hace el modelo del universalismo no absolutista. Para ilustrar el tipo de diferencia que existe entre un universalismo que se compromete con principios que expresan razones pro tanto y un particularismo que sólo puede aceptar que los principios, prima facie, expresen razones, cabe recordar las diferencias que Jon Elster señala entre un modelo de decisión basado en la negociación y un modelo basado en la argumentación estratégica. La aplicación de este último modelo no garantiza resultados diferentes de los que se obtienen a través de una negociación. Sin embargo, la adopción de uno u otro representa una diferencia teórica y práctica apreciable porque, ciertamente, pueden, y tienden a, producir resultados distintos pero, sobre todo, porque la implementación de sendos modelos, independientemente del resultado, exhibe y se compromete con valores diferentes.

2.6. Creo que es posible poner en duda la tesis de Celano acerca de la superioridad del concepto particularista de razón. Siguiendo el razonamiento de este autor, la propuesta particularista tiene una innegable capacidad explicativa respecto de nuestro razonamiento conversacional ordinario y de nuestro razonamiento moral. Consecuentemente, en la medida en que el razonamiento moral u ordinario se incorporan al ámbito jurídico, el particularismo adquiere protagonismo también en este terreno. Sobre esta base, y dada la efectiva incorporación de principios morales en nuestras constituciones, Celano concluye que el razonamiento moral particularista invade el ámbito jurídico haciendo imposible cualquier intento no banal de distinción. Supongamos que esto es cierto. Ello probaría que las normas primarias del derecho son tratadas por las autoridades como generalizaciones que prima facie establecen derechos y deberes jurídicos pero que son siempre 
transparentes respecto de las propiedades que las autoridades consideran moralmente relevantes en un caso particular.

Ahora bien, una clásica distinción entre derecho y moral sostiene justamente que en la moral está ausente la idea de autoridad tal como se presenta en el ámbito jurídico. Por ello, los sistemas morales son estáticos, no contienen normas que regulen la creación y eliminación de normas ${ }^{26}$. Si es que hay una noción comprensible de autoridad moral, ella es distinta de la de autoridad jurídica. Las normas jurídicas primarias presuponen la existencia de autoridades jurídicas y éstas a su vez presuponen normas secundarias que establecen propiedades relevantes para decidir quién debe decidir, i.e. quién tiene competencia para crear, extinguir y administrar normas (razones) jurídicas en los casos concretos. Si la (meta)decisión acerca de quién crea o aplica las razones jurídicas se apoyase en las características relevantes de cada caso particular tendríamos un modelo de decisión perfectamente particularista, pero no tendríamos autoridades tal como se conciben en los sistemas jurídicos contemporáneos. La existencia de autoridades, i.e. la existencia de normas secundarias, surge justamente para resolver el problema que presentaría un modelo de decisión totalmente particularista. Esto es tanto como decir, que un modelo de decisión totalmente particularista podría dar cuenta de un sistema de derecho primitivo, o de una sociedad pequeña, pero no de los ordenamientos jurídicos contemporáneos.

Aun admitiendo que un modelo de razonamiento particularista pudiese explicar qué y cómo se decide jurídicamente, es decir, aquello que deciden y la forma en que lo hacen los jueces o cualquier autoridad jurídica, no puede -por razones conceptuales- explicar la noción ni la existencia de las autoridades jurídicas. Afirmar que la (meta)decisión acerca de quién decide en el derecho es también una decisión particularista equivale a negar que hay autoridades jurídicas, puesto que tener una autoridad implica que aceptamos pautas que fijan por anticipado quién toma dichas decisiones o,

${ }^{26}$ H.L.A. Hart (1961), cap. 8. 
lo que es lo mismo, que la (meta)decisión acerca de quién decide no se hace en cada caso individual de decisión. La existencia de autoridades "resuelve" el problema o el defecto del carácter estático e ineficaz que presentaría un conjunto de normas de carácter primario justamente porque su existencia significa que tenemos un modo no particularista para decidir quién las crea y las aplica.

No lo argumentaré aquí porque no es el objeto de la reflexión, pero, a mi modo de ver, el derecho incorpora una pretensión de establecer razones invariablemente relevantes. Esta pretensión, sin lugar a dudas, puede fallar. Y, si aceptamos la reconstrucción de Celano, cabe reconocer que, respecto de nuestros derechos y deberes jurídicos, dicha pretensión de hecho falla. Sin embargo, ello no alcanza para demostrar que no existe, es inapreciable o se apoya en una tesis mal formada. En todo caso, si la pretensión en ningún caso lograse efectivizarse podría considerarse que estamos ante un indicador de su banalidad, o de la existencia de un defecto insuperable. Si se acepta lo dicho en los párrafos precedentes, éste no es el caso, y el carácter nomodinámico del derecho ofrece un argumento decisivo. No es verdad que todas las razones que ofrece el derecho quedan bien explicadas desde una perspectiva particularista. Si lo fuese, ello implicaría que no existen autoridades jurídicas y que el derecho no consiste en un conjunto de pautas justificativas que auto-regula su propia creación y aplicación. Como sabemos, las autoridades jurídicas, al igual que todos los derechos y obligaciones jurídicos, dependen y son establecidas mediante normas jurídicas. Si estas normas secundarias fuesen concebidas del mismo modo en el que Celano concibe las generalizaciones normativas que establecen derechos y obligaciones, i.e. como estableciendo razones particularistas e indeterminadas, no dispondríamos de algún modo para identificar de antemano quién puede o debe tomar decisiones jurídicas, es decir, no habría autoridades jurídicas. Conforme a una idea unánimemente admitida, un conjunto de normas (o razones) que no auto-regula su producción y aplicación no puede ser caracterizado como derecho o, al menos, padecería graves defectos. La 
ausencia de autoridades implicaría el carácter estático del sistema y, visto que las normas no se auto-aplican, implicaría también su absoluta ineficacia para resolver conflictos y dirimir la cuestión de si una norma primaria ha sido o no violada. Presuponer que un modelo particularista explica las razones que ofrece el derecho permite articular una reductio ad absurdum de la que se extrae como consecuencia que no existen autoridades jurídicas. Ello es así porque las normas que establecen autoridades jurídicas no tienen una plausible lectura particularista. Si la pretensión de universalidad de las normas que establecen autoridades fracasase, entonces no existirían autoridades jurídicas. En otras palabras, la existencia de autoridades es la prueba del éxito de la pretensión de universalidad de algunas normas secundarias del sistema.

Visto que negar la existencia de autoridades puede considerarse cuanto menos exagerado -al menos hasta que la invasión de la moral no sea total- e inclusive contradictorio si presuponemos la existencia de un sistema jurídico tal como contemporáneamente se lo entiende, se puede decir que esto constituye una demostración de que, entre las razones que ofrece el derecho, al menos algunas deben ser invariablemente relevantes y no podrían ser correctamente explicadas desde una perspectiva particularista ${ }^{27}$.

2.7. Para concluir con mi respuesta quisiera hacer explícito que, bajo los supuestos del análisis de Celano, él está acertado al decir que no podemos elegir "nuestro" concepto de razón. Lo está porque, en su perspectiva, analizar "el" concepto de razón es tratar de conocer la noción de razón que está implícita en el modo en el que efectivamente razonamos -obviamente, siempre y cuando haya un modo en el que efectivamente razonamos-. Como he

\footnotetext{
${ }^{27}$ Esta reflexión sirve para argumentar la posición que he ya defendido en trabajos anteriores según la cual la noción positivista de derecho presupone que al menos algunas de sus normas sean "normas genuinas". Al respecto, puede verse la posición crítica de J.C. Bayón en J.C. Bayón y J. Rodríguez (2003), pp. 204-208.
} 
dicho al inicio, mi trabajo no perseguía este objetivo, sino aquel de identificar los diversos modos de concebir la noción de razón propuestos por dos concepciones filosóficas que discuten acerca de cuál es "nuestro" concepto de razón. Ahora bien, mi tesis acerca de que ambos conceptos son lógica y empíricamente admisibles es equivalente a decir que cualquiera de ellos podría serlo. No hay un motivo lógico o empírico por el cual uno de ellos deba considerarse inadmisible o, por el contrario, necesario. Esto ciertamente no obsta al hecho que sólo uno de ellos, contingentemente, sea "nuestro" concepto de razón. En oposición a esta tesis, Celano ofrece fundamentalmente dos tipos de argumentos tendientes a mostrar la superioridad del concepto particularista y el carácter insatisfactorio del concepto universalista. El concepto universalista de razón se debe abandonar, o bien porque se apoya en una tesis mal formada y, en este sentido, aun queriendo implementarlo no es posible hacerlo. O bien, simplemente porque no es nuestro concepto de razón, no explica el modo en que efectivamente razonamos. En esta respuesta, en contraposición con estas dos tesis, he sostenido, en primer lugar, que no se han ofrecido razones suficientes para mostrar que la idea universalista presenta un defecto lógico o empírico insuperable y, en segundo lugar, que la reconstrucción de "nuestro" concepto de razón vigente en la práctica ordinaria de argumentación moral no es el único objetivo teórico por el cual interesa precisar el concepto de razón universal. El modelo de razonamiento universalista, por ejemplo, es propuesto como un ideal regulativo en ciertos ámbitos de razonamiento. Asimismo, en mi opinión, éste de hecho es el concepto incorporado en "nuestro" concepto de derecho. Que esta noción de derecho esté siendo abandonada y que llegue a ser totalmente reemplazada por otra, apoyada en una forma de razonamiento particularista, es algo ciertamente posible; pero este posible cambio en las formas de razonamiento jurídico lejos de ser una prueba en contra de la idea propuesta en mi trabajo, mostraría que en relación a un ámbito específico es posible defender deliberadamente, y en este sentido "elegir", ya sea preservar un 
patrón de razonamiento o instaurar uno nuevo ${ }^{28}$.

\section{Sobre razones y normas. Respuesta a José Juan Moreso}

3.1. Creo que Moreso tiene razón al poner el acento en que, al menos en este contexto, la presentación más interesante del debate universalismoparticularismo es aquella que se concentra en el contraste de dos modelos de racionalidad, independientemente de la base metafísica que dicho contraste pueda tener. Esto no significa ignorar que parte importante del debate de la filosofía moral se presenta en términos metafísicos. Más por amor a la precisión que por defender una posición al respecto creo que es conveniente recordar que cuando en mi trabajo afirmo que "una concepción universalista de las normas es compatible con el realismo, el anti-realismo, el cognitivismo, el no-cognitivismo, etc." citaba a Shafer-Landau, quien se refiere específicamente a la universalidad de la estructura lógica de las normas. Según dicho autor, el hecho de atribuir a las normas la forma lógica de condicional universal es compatible con las distintas teorías metaéticas acerca de su status ontológico, pero sería excesivo afirmar que dicho autor acepta la compatibilidad del universalismo con cualquier teoría metaética. En todo caso, si dejamos de lado la discusión metafísica para concentramos exclusivamente en los distintos modelos de toma de decisión, creo que no hay lugar a dudas acerca de la compatibilidad entre el modelo universalista

\footnotetext{
${ }^{28} \mathrm{Al}$ respecto, debo parcialmente corregir y precisar lo que he sugerido en mi trabajo original. El concepto de razón jurídica vigente en nuestro concepto de derecho no depende de una “elección” teórica. Pero, en la medida en que, por una parte, tenemos un concepto de derecho, i.e. somos conscientes de él y lo analizamos teóricamente y, por otra parte, aceptamos que el derecho es una institución social, susceptible de modificarse (en modo deliberado o no), los participantes de cuyas prácticas el derecho depende pueden (deliberadamente o no) provocar cambios en la forma de concebir el razonamiento jurídico. En la medida en que es posible una tentativa de cambio (o preservación) deliberada cabe admitir que el concepto incorporado en nuestra práctica puede ser parcialmente fruto de nuestra "elección".
} 
apoyado en normas en sentido estricto con las distintas teorías acerca del status ontológico de las mismas. El universalismo de las razones presupone la posibilidad del conocimiento de normas universales, pero no sostiene que dichas normas sean a su vez fruto del conocimiento de una realidad moral independiente de nuestras actitudes y comportamientos.

Moreso no cree necesario o especialmente útil distinguir los tres sentidos de universalidad que he señalado en mi trabajo. A continuación intentaré mostrar por qué la utilidad de dicha distinción sigue en pié a pesar de las precisiones de Moreso. En "Razones y Normas" he mencionado, en primer lugar, una noción de universalidad en sentido semántico. Siguiendo a Alchourrón y Bulygin, con esta noción hago referencia a dos cosas: a que las normas regulan clases de casos -no casos individuales- y a que, bajo esta presuposición, la normas regulan clases más o menos generales. $\mathrm{O}$, si se quiere, más o menos específicas. La universalidad en este sentido deviene una propiedad gradual.

La universalidad semántica de un enunciado condicional deóntico no garantiza que éste sea un condicional estricto (universal) en sentido lógico, $y$, sobre todo, es irrelevante para establecer si él expresa o no una razón invariable (universal). En otras palabras, éste no es el sentido de universalidad que define a una posición universalista respecto de las razones y, en efecto, el particularista no niega que podamos formular enunciados normativos que, desde una perspectiva semántica, son universales. En mi trabajo no he tratado de negar que, como indicador del hecho que un enunciado expresa razones invariables para la acción, la universalidad semántica de los enunciados normativos es trivial o irrelevante ¿Es ésto motivo suficiente para afirmar que su distinción es irrelevante? En mi opinión, la importancia de la distinción de este sentido semántico de universalidad es directamente proporcional a su irrelevancia como indicador de que un enunciado expresa, o nos compromete con, razones universales. Esta noción de universalidad está presupuesta y es unánimemente atribuida a los enunciados que expresan normas jurídicas, pero nada indica acerca del tipo de razones que dichos 
enunciados expresan. Subrayar la diferencia entre este sentido de universalidad y los restantes es crucial justamente porque ella permite mostrar que algunos autores, entre los que en mi opinión se cuenta Moreso, defienden la universalidad de las normas jurídicas sólo en este sentido irrelevante. Entiéndase bien, irrelevante al fin de garantizar un compromiso con el universalismo respecto de las razones que ofrece el derecho.

3.2. El segundo tipo de universalidad, la universalidad lógica de los condicionales que expresan normas, es también condición necesaria pero no suficiente para que dichos condicionales expresen razones invariables. Desde un punto de vista lógico, es usual distinguir entre condicionales estrictos y derrotables, donde la diferencia reside en que los primeros, y no los segundos, son condicionales cuantificados universalmente respecto de las circunstancias. Un particularista puede aceptar que una decisión racional, a primera vista, se apoya en normas, pero pondrá el acento en que dichas normas son siempre condicionales revisables o derrotables. Por el contrario, un universalista, puede aceptar que una decisión racional, a primera vista, se apoya en normas derrotables, pero pondrá el acento en que dichas normas derrotables, debidamente revisadas, son siempre condicionales estrictos o inderrotables.

En mi trabajo he citado a Alchourrón en la medida en que él analiza la distinción entre condicionales lógicamente derrotables e inderrotables, pero no he asumido, ni doy por descontada, su tesis lógica universalista según la cual los condicionales derrotables deben definirse y reducirse a condicionales cuantificados universalmente. Ciertamente, si se asume esta tesis, desaparece la distinción entre dos tipos de condicionales, puesto que, como bien nos recuerda Moreso, para Alchourrón los condicionales derrotables son en realidad condicionales inderrotables enmascarados. Es decir, condicionales estrictos cuyo antecedente contiene un operador de revisión. Este operador representa un conjunto de propiedades implícitas que, en conjunción con aquellas explícitamente mencionadas, garantizan la obtención del consecuente 
y tornan aplicables las reglas lógicas del refuerzo del antecedente y el modus ponens. Sin embargo, la aplicabilidad al razonamiento práctico de está propuesta de Alchourrón es lo que un particularista pone en cuestión.

Un particularista piensa que esta tesis, formalmente irreprochable, carece de todo interés práctico porque no hay manera de saber, con anticipación a una situación de decisión concreta, cuáles son las propiedades que, unidas al antecedente explícito, tornan inderrotable el condicional. Esto es tanto como decir que los enunciados normativos, i.e. los condicionales que conectan la presencia de ciertas circunstancias a un consecuente deóntico, son siempre revisables a la luz de la situación en que efectivamente se decide. Por este motivo, el particularista sostiene la inadecuación de los condicionales estrictos a la hora de reconstruir el razonamiento práctico.

En otras palabras, la tesis de Alchourrón, que hace suya Moreso -y también Caracciolo-, es que estos condicionales derrotables pueden ser reconstruidos como condicionales estrictos que contienen en sus antecedentes un operador de revisión representante de todas las condiciones implícitas que permitirán razonar deductivamente. Sin embargo, la respuesta de quien se niegue a esta reducción universalista será que esto podría ser el caso sólo si fuese posible concebir un operador de revisión que diese monotonicidad al razonamiento. Pero ello no es posible porque por ejemplo, según Brandom, este tipo de operador, u otras cláusulas similares, no son eliminables, "su contenido no puede hacerse explícito bajo la forma de una serie de premisas adicionales; no son una abreviación de algo que podríamos decir, si dispusiésemos del tiempo o del deseo de hacerlo. "El problema no es sólo que necesitaríamos excluir una lista infinita de condiciones -aunque eso es cierto-. Es que no se podría definir la pertenencia a esa lista: no sabemos cómo especificar de antemano lo que pertenece a la lista" ${ }^{29}$. La tentativa de presentar el contenido de estas normas derrotables como una relación universal según la cual 'ceteris paribus, q se sigue de p' -o utilizando el

${ }^{29}$ R. Brandom (2000-2002), p. 109. 
lenguaje de Alchourrón: '(F)p $\rightarrow$ q' - "significa que 'q se sigue de $p$, a menos que existan condiciones que la disconfirmen o que interfieran'. Pero esto es lo mismo que decir que q se sigue de p excepto en los casos en que, por alguna razón, no lo hace" ${ }^{30}$. Según Brandom, la necesidad de agregar este tipo de cláusulas es señal exactamente de lo contrario de lo que pretende el universalista. Ellas, lejos de operar como un Deus ex machina que elimina mágicamente la no monotonicidad de la inferencia, en realidad constituyen una señal explícita de su no monotonicidad ${ }^{31}$.

En resumen, esta concepción de las normas como condicionales derrotables revisables, no sólo no capta sino que tergiversa el sentido en que, en una óptica particularista, las normas serían derrotables o revisables. La idea que la propuesta de Alchourrón podría captar, en todo caso, es la de principio universal en contraste con la de regla universal. Pero esta noción de principio que expresa una condición contribuyente, presupone que el antecedente es completable, es decir, que existe un conjunto último de condiciones que, en modo invariable, permite obtener la consecuencia deóntica. El particularismo niega esta posibilidad. Las generalizaciones normativas son derrotables, pero no porque sus antecedentes están incompletos sino porque están -en modo irremediable- sólo contingentemente relacionados con sus consecuentes. No es posible "completarlos" en modo tal que la relación devenga universal o necesariamente verdadera.

En su momento he tratado de subrayar que la polémica universalismoparticularismo tampoco queda captada a través de este debate lógico acerca del carácter estricto o derrotable de las normas.

La lógica es sólo un instrumento para expresar o representar diferentes ideas, en este caso, sobre las razones y el razonamiento práctico. Según un

\footnotetext{
${ }^{30}$ R. Brandom (2000-2002), p. 109. También J. Dancy subraya que los principios morales serían de poco interés si lo que dicen es que p es una razón a menos que algo ocurra e impida que lo sea. Cfr. J. Dancy (1999), p. 28. Este autor muestra que el problema en relación a los principios no es que sean incompletos sino que no establecen un "pattern" que permita correlacionar las propiedades naturales con las propiedades evaluativas.

${ }^{31}$ R. Brandom (2000-2002), p. 109.
} 
universalista podemos identificar, con antelación a un caso concreto, un conjunto de propiedades invariablemente relevantes. En contraste, para el particularista no es posible, antes de relevar las características del caso individual, delimitar un conjunto de condiciones relevantes desde un punto de vista práctico. En el primer caso, se admiten normas universales y, desde un punto de vista lógico, es correcto decir que ellas tienen la forma de condicionales estrictos. En el segundo, o bien no se admiten normas en absoluto o bien, si se admiten, es correcto decir que, desde un punto de vista lógico, ellas no se comportan como condicionales estrictos, ni son reducibles a ellos. Son condicionales derrotables.

3.3. Esto me permite pasar a considerar el tercer sentido de universalidad, que hace referencia a la idea sustancial cuya correcta representación lógica se está buscando: la relevancia invariable de ciertas propiedades. Decir que una norma es universalmente relevante presupone que ella es universal desde un punto de vista lógico y semántico, pero agrega la siguiente información: afirma que tal norma genera razones para la acción. Según he tratado de defender en mi trabajo, ésta es la noción de universalidad sobre la que discuten el universalismo y el particularismo. El primero afirma que es posible identificar un conjunto finito de normas universalmente relevantes, i.e. que generan razones invariables. El segundo lo niega. Sostuve en mi trabajo que la posición particularista respecto de la relevancia práctica de las "normas" puede presentarse de dos maneras posibles, justamente, porque depende de como se configuren las "normas". Una vía posible es aceptar el concepto universalista de norma, en cuyo caso el particularista debe negar que haya normas válidas o relevantes desde un punto de vista práctico; una segunda alternativa es abandonar el concepto universalista y asumir una noción de norma derrotable, genuinamente diferenciable del anterior, en cuyo caso el particularista no necesita negar su validez o relevancia.

Moreso sostiene que las dos formas o vías que propongo, en realidad, son equivalentes. Según este autor: "Lo que el particularista desafía es que 
pueda haber normas válidas, precisamente". Intentaré mostrar por qué esta última afirmación es engañosa y las dos vías que propongo son diferentes. El particularista niega que pueda haber normas válidas si, y sólo si, se mantiene un concepto universalista de norma. $\mathrm{Si}$, en cambio, reemplazamos tal concepto por otro, no reducible a norma universal, la afirmación de Moreso es falsa. De hecho, el particularista no necesita negar la relevancia de las normas derrotables, siempre y cuando no se crea que ellas son reducibles a normas universales. Para que un particularista pueda asumir, sin contradicción, la existencia o la relevancia de normas o, en general, dar cuenta de la noción de normatividad es imprescindible presuponer que las normas no son reconducibles a condicionales universales o, lo que es lo mismo, que el concepto de normatividad no incluye como elemento la universalidad. Ciertamente, a este punto se debe afrontar la pregunta que formula Caracciolo. En qué sentido estas normas son genuinamente normas y no meras generalizaciones descriptivas. Al respecto me remito a lo que he dicho antes, sobre cuya base he afirmado que el particularismo sostiene un desacuerdo conceptual con el universalismo respecto a la noción de normatividad.

Según Moreso, el aporte de Alchourrón mostraría que "no basta para el particularismo concebir las normas como el contenido de condicionales derrotables, sino que debe añadirse que dichos condicionales no puedan, por razones conceptuales, ser sujetos a revisión". Si el particularismo pudiese producir una demostración general como la que pide Moreso habría demostrado incontrastablemente que la admisión de condicionales universales, por razones conceptuales, es inconducente. En mi opinión, el particularismo no dispone de una prueba general de este tipo, pero ciertamente su tesis es que tal prueba se puede ofrecer respecto del razonamiento práctico -y por ejemplo, eso es lo que intenta demostrar Celano-. Por este motivo, aunque no haya ningún obstáculo lógico a la propuesta de Alchourrón, i.e. a la posibilidad de revisión de los condicionales derrotables, un particularista asegura que tal revisión es impracticable y por ello improponible respecto del razonamiento práctico. En otras palabras, presupone que en el ámbito práctico la propuesta de Alchourrón no debe ser aceptada. 
Moreso reconoce que el particularista rechaza el concepto de norma universal y la reconstrucción lógica de las normas como condicionales cuantificados universalmente respecto de las circunstancias. Sin embargo, parece no advertir que, aunque no lo dice explícitamente, esto implica que el particularista rechaza la propuesta de Alchourrón, es decir, rechaza la reconstrucción lógica de las normas como condicionales derrotables sujetos a revisión, i.e. reconducibles a condicionales cuantificados universalmente. Como he dicho antes, el particularista no debe necesariamente adoptar un concepto alternativo de norma, o normatividad; en rigor, podría abandonar por completo estas nociones o declararlas irrelevantes. Pero si no escoge esta vía, es decir, si continua hablando de normas, en algún sentido, no puede hacer referencia al concepto de norma derrotable propuesto por Alchourrón. Si lo hiciese caería en contradicción.

Si aceptamos esta idea de norma derrotable, no reducible a aquella de norma universal incompleta, entonces sí se puede ver lo que Moreso niega, i.e. que, en relación a este punto, hay dos presentaciones posibles y no equivalentes del particularismo. Una niega la relevancia o validez de las "normas", donde éstas son condicionales universales estrictos, la otra puede aceptar la relevancia o validez de las "normas", donde éstas no son, ni pueden reducirse a, condicionales universales estrictos.

A mi juicio, la distinción de tres sentidos de universalidad es sumamente útil para despejar ambigüedades y precisar un discurso que se presta a declaraciones retóricas. Tal como lo demuestran las tesis de numerosos juristas, la universalidad semántica y lógica de las normas puede admitirse sin necesidad de asumir su relevancia universal. La distinción es especialmente útil en el ámbito jurídico puesto que permite desvelar por qué algunas posiciones que en principio aceptan, sin precisar en qué sentido, la universalidad de las normas jurídicas, no son en realidad universalistas respecto de las razones jurídicas. Ello ocurre cuando, si bien desde un punto de vista lógico y semántico se acepta la universalidad de dichas normas, no se está dispuesto a sostener la tesis de la relevancia invariable de las propiedades mencionadas en sus antecedentes. 
3.4. En el punto IV de su trabajo, Moreso intenta defender una tesis universalista limitada. Según Moreso, frente al desafío particularista, el universalista tiene a disposición la estrategia de la especificación de sus principios. Es decir, cuando se advierte un contraejemplo, el universalista debe precisar las condiciones de aplicación de las normas válidas, y, mientras pueda responder de este modo, el reto particularista no representa un problema sino que constituye un estímulo para hacer explícito y delimitar mejor el contenido de las normas universales. Comparto esta opinión de Moreso y otros autores aunque estimo que la especificación de los principios universalistas no tiene por qué ser considerada una estrategia defensiva del universalismo ante una dificultad planteada por el particularismo. En realidad se trata de un requisito indispensable de identificación de los principios o normas universales que expresan propiedades invariablemente relevantes. Ciertamente, la formulación completa de las normas incluye la indicación de todos sus defeaters, y justamente esto es lo que el particularismo sostiene que es imposible hacer antes de afrontar un caso concreto. De todas formas, debe recordarse que la especificación de las normas universales tiene un presupuesto límite. Adoptando el lenguaje de Celano, el universalista tiene que aceptar la existencia de una tesis de relevancia última que establece el conjunto completo de propiedades relevantes. En otras palabras, el conjunto de condiciones de aplicación de las normas no sólo es estable sino también completamente definido o delimitado, es decir, determina de antemano todas las propiedades relevantes.

Respecto de este problema, Moreso plantea una cuestión importante. ¿Pueden las normas, en una concepción universalista, incluir condiciones de aplicación evaluativas? Como nos recuerda este autor, es usual que las normas juridicas incorporen defeaters o condiciones de aplicación evaluativos. Por ejemplo, entre las causas de justificación del homicidio figura la legítima defensa. El universalismo sostiene la posibilidad de establecer, a través de normas universales, una correlación estable entre ciertas propiedades naturales (antecedente) y ciertas propiedades evaluativas o normativas 
(consecuente). La presencia de propiedades evaluativas en el antecedente de una norma $\mathrm{N} 1$ requiere que podamos disponer de otra norma $\mathrm{N} 2$ que delimite las condiciones de aplicación de tales propiedades. En el caso del ejemplo necesitamos otra norma que establezca las propiedades naturales en presencia de las cuales podemos calificar a una defensa como legítima. Si esto no es posible, si la idea evaluativa de legitimidad no puede correlacionarse en modo estable con la presencia de un conjunto definido de propiedades naturales, la idea del universalismo fracasa. Al respecto, Moreso hace explícita una precisión fundamental: una tesis de relevancia última es concebible sólo de manera relativa a un universo de discurso delimitado. Sobre este punto creo que es interesante detenerse brevemente para realizar dos precisiones interesantes. La tesis universalista es relativa al menos en dos sentidos. Como he dicho anteriormente, el universalismo es compatible con que el ámbito de razones del cual se predica (por ejemplo, la moral o el derecho) sea parcialmente indeterminado. Entre otros sentidos de "indeterminación", el universalismo puede admitir que haya problemas o preguntas que carezcan de una respuesta normativa de carácter universal. Si esto es así, se sigue que el universalismo puede coherentemente defenderse en relación a un conjunto limitado de problemas normativos. El universalismo no promete que para cualquier pregunta práctica hay una respuesta deóntica de carácter universal. En otras palabras, la tesis de relevancia presupuesta por el universalismo tiene carácter definido, estable y último, pero limitado, no es omnicomprensiva. El conjunto de las propiedades invariablemente relevantes que conforman la tesis de relevancia última, como señala Moreso, es relativo a un universo de discurso.

Sin embargo, también es importante recordar que la tesis de relevancia última es el resultado de la presuposición de un conjunto de normas universales y estas normas, individualmente consideradas, sí establecen un conjunto de propiedades que además de ser definido y estable es completo, y por ello suficiente, en relación a una consecuencia normativa. En otras palabras, el conjunto de propiedades relevantes que cada norma universal 
propone es siempre completo en relación a la solución o calificación deóntica de una acción ${ }^{32}$.

Si se acepta esta distinción entre el carácter relativo de la tesis de relevancia última (i.e. del conjunto de propiedades relevantes que emerge de un conjunto de normas universales) y el carácter relativo del conjunto de propiedades relevantes que establece una norma universal, es posible advertir también la diferencia entre dos sentidos en que la tesis universalista presupone una regla de clausura respecto de la relevancia ${ }^{33}$. Cada norma universal establece un conjunto suficiente de propiedades relevantes en relación a una específica solución normativa y, por ello puede decirse que ella, o más precisamente su antecedente, está asociado a una regla de clausura respecto de la relevancia. Pero, lo está en el sentido de que el antecedente de la norma excluye la posibilidad de introducir nuevas condiciones (positivas o negativas) de aplicación de la consecuencia deóntica prevista por tal norma. Una norma cuyo antecedente no está asociado a este tipo de regla de clausura no es universal sino derrotable. Sin embargo, esto no significa que cualquier otra propiedad no mencionada en una norma universal sea irrelevante en relación a la acción regulada, puesto que si existen otras normas, $y$, adicionalmente, si se acepta la posibilidad de que

\footnotetext{
${ }^{32}$ En realidad la idea de propiedad invariablemente relevante no relativa a la calificación deóntica de una acción o decisión carece de sentido para un universalista. Ello es así porque una propiedad natural es invariablemente relevante sólo porque es una condición que permite obtener, como consecuencia, la calificación deóntica de una acción.

${ }^{33}$ La expresión "regla de clausura respecto de la relevancia" ha sido propuesta por J. Rodríguez y G. Sucar y discutida por J.C. Bayón en J.C. Bayón y J. Rodríguez (2003). Estos autores no distinguen los dos sentidos que propongo a continuación. En principio, ellos asocian una regla de clausura respecto de la relevancia a la noción de norma universal y no a la de tesis de relevancia última; asimismo, piensan esta regla como un expediente que garantiza la relevancia invariable del antecedente de la norma pero que, a la vez, excluye la relevancia de cualquier otra propiedad. Consecuentemente, para estos autores, las normas no sólo establecen razones universales sino tambien finales o concluyentes. A tenor de mi propuesta, en cambio, las normas establecen razones universales y últimas, en el sentido de estables o no maleables, mientras que la tesis de relevancia sí es un conjunto de razones últimas en el sentido de finales o concluyentes.
} 
haya conflictos no resueltos entre ellas, podrían existir otras propiedades relevantes, i.e. otras normas, que califican deónticamente la misma acción en modo incompatible. Ahora bien, aunque los conflictos son posibles y probablemente usuales, un conjunto de normas universales debe establecer una respuesta final o concluyente al menos en relación a algunos casos, de lo contrario estaría totalmente indeterminado. En otras palabras, no todas las normas pueden estar en conflicto ${ }^{34}$. Sobre esta base, puede afirmarse que hay otro sentido en el que el universalismo presupone una regla de clausura respecto de la relevancia, que está asociada, no a cada norma universal, sino a la tesis de relevancia, i.e. al conjunto de propiedades relevantes que emerge de un sistema normativo en su conjunto y no de cada norma singularmente considerada. Este tipo de regla de clausura exige considerar irrelevante cualquier otra propiedad no comprendida en dicho conjunto. Desde esta perspectiva, si un sistema normativo no está asociado a una regla de clausura respecto de la relevancia no permitiría resolver ningún caso individual. Es decir, si la tesis de relevancia de una propuesta universalista no está asociada a este tipo de regla de clausura respecto de la relevancia no es última, en el sentido de final o concluyente. En mi trabajo, con un lenguaje diferente, me he esforzado en destacar que un universalista no tiene por qué aceptar una regla de clausura, así interpretada, en relación a cada norma universal. Si lo hace, no es sólo universalista sino también absolutista, en el sentido que Shafer-Landau da a este término. Es decir, acepta que una vez identificada una norma, cualquier otra propiedad debe ser considerada irrelevante en relación a la solución normativa establecida ${ }^{35}$.

En resumen, un universalista tiene que aceptar que las normas están necesariamente asociadas a una regla de clausura respecto de la relevancia,

\footnotetext{
${ }^{34}$ En el lenguaje de Rodríguez esto significa que deben existir meta-normas que, estableciendo jerarquías entre las normas, resuelvan los conflictos que se presenten, y que si bien dichas meta-normas pueden ser condicionales derrotables en el sentido de Alchourrón, no todas pueden ser genuinamente derrotables en el sentido que Bayón confiere a esta expresión.

${ }^{35}$ Este es claramente el caso de J.C. Bayón. Cfr. J.C. Bayón y J. Rodríguez (2003), p. 189.
} 
entendida en el primer sentido, regla que garantiza que las normas son inderrotables. Pero no tiene por qué aceptar que las normas estén asociadas a una regla de clausura entendida en el segundo sentido, regla que garantizaría que las normas establezcan soluciones concluyentes o finales $y$, consecuentemente, que no haya conflictos entre normas.

3.5. Probablemente la falta de distinción entre las características predicables de las normas universales y aquellas predicables de la tesis de relevancia universal, o la creencia de que el universalismo compromete necesariamente con una tesis de relevancia última no relativa o limitada a un universo de discurso es lo que lleva a Celano a pensar que la idea está mal formada. En opinión de Moreso "Para microsistemas así concebidos la operación de revisión estable es alcanzable y permite pasar, en este contexto limitado, de la formulación de defeaters evaluativos a defeaters descritos mediante propiedades naturales". Sin embargo, cabe recordar que esta posibilidad no es siempre concretizable, lo que equivale a decir que no contamos con normas universales para todos y cada uno de los problemas prácticos que nos podemos plantear o para cualquier universo de acciones que podamos hipotizar. Pero esto no significa que el universalismo sea inviable, sino que no cubre todo nuestro espacio moral o jurídico. Habrá problemas prácticos (jurídicos o morales) que no pueden ser resueltos mediante la aplicación de normas universales.

Las consideraciones planteadas por Moreso permiten inferir que, en su opinión, es posible defender un universalismo limitado en el ámbito moral. Sin embargo, y a partir de lo que el autor sostiene en el punto $\mathrm{V}$ de su trabajo, no creo que pueda decirse lo mismo por cuanto se refiere al ámbito jurídico. En este último apartado Moreso critica mis apreciaciones en relación a Dworkin y al Positivismo Inclusivo a propósito de la relación entre derecho y moral. Esta crítica pone en evidencia la necesidad de precisar la idea que intento defender en mi trabajo. La tesis que sugiero puede resumirse en una sola frase y consiste en que no es posible sostener una concepción 
universalista de las razones jurídicas y, contemporáneamente, una concepción derrotable de las normas que las establecen ${ }^{36}$. Desde este punto de vista, aquellas posiciones que admiten el carácter derrotable de las normas jurídicas en virtud de la aplicación de principios morales -aun cuando no lo reconozcanabandonan una condición que es necesaria para que aquellas expresen razones invariablemente relevantes. Esto, sin embargo, no significa que sean particularistas ya que pueden sostener, paralelamente, el carácter universal de los principios morales que derrotan a las normas jurídicas. Esta tesis tiene un presupuesto obvio: que se puedan identificar y distinguir las normas jurídicas de las normas morales.

Estoy de acuerdo con Moreso en que el modo en que yo planteo la relación entre derecho y moral "no es el modo en que el Positivismo Inclusivo y Dworkin plantean la cuestión de las relaciones entre Derecho y moral". En mi perspectiva, el problema bajo consideración es si las normas jurídicas confieren o no razones invariablemente relevantes, no si estas últimas razones -supuesto que se admitan- deben prevalecer sobre otros tipos de razones. La pregunta acerca de si el derecho ofrece razones y, en su caso, qué tipo de razones ofrece, no es un debate acerca de la justificación última de las decisiones. Afirmar que el derecho ofrece razones de carácter universal significa que sus normas establecen propiedades invariablemente relevantes. Como traté de precisar mas de una vez, "universal" no quiere decir absoluto, ni concluyente, ni final. Por este motivo, a diferencia de lo que piensa Moreso, y bajo la hipótesis de que se admita la traslación del debate universalismoparticularismo al ámbito jurídico, este debate plantea una pregunta previa e independiente de la cuestión acerca de qué tipo de razones prevalece, es decir, previa e independiente de la tesis de la supremacía de las razones morales y de la unidad del razonamiento práctico.

\footnotetext{
${ }^{36}$ Se hace engorroso repetirlo en cada oportunidad, pero cuando hablo de normas derrotables entiendo que estas son distintas de las inderrotables, es decir, no reducibles a ellas como propone Alchourrón.
} 
Moreso analiza el problema de si las normas jurídicas generan razones para la acción directamente desde la perspectiva de la unidad del razonamiento práctico. En mi opinión, se trata de dos debates que conviene separar, sobre todo porque la tesis de la unidad del razonamiento práctico puede interpretarse en formas diversas. No obstante ello, es interesante ver lo que se sigue de la propuesta de este autor.

Conforme a la opinión explícita de Moreso, la tesis de la unidad del razonamiento práctico implica necesariamente la tesis de la supremacía de la moral ${ }^{37}$. Ahora bien, cabe añadir, tal como está presentada, supone además que las normas jurídicas no generan razones. Según este autor: “cuando lo que requiere el derecho es contrario a lo requerido por la moral, la identidad de las normas jurídicas queda intacta, pero su relevancia práctica queda afectada". Es decir, no constituyen razones. Las normas jurídicas, o bien porque coinciden con la moral, o bien porque contrastan con ella, en ningún caso son capaces de generar razones o alterar aquellas existentes ${ }^{38}$. A diferencia de lo que sostiene Moreso, creo que esta idea presenta una tesis problemática, sobre todo cuando se piensa en derechos democráticos cuyas normas -que pueden requerir algo contrario a la moral- son establecidas por autoridades legítimas. En todo caso, no discutiré aquí esta cuestión, ya que mi apreciación crítica no estaba sólo dirigida a esta hipótesis de conflicto entre derecho y moral, en la que abiertamente Moreso reconoce que las normas jurídicas no constituyen razones para la acción. Me interesaba principalmente criticar aquellas posiciones que, bajo un aparente compromiso con una tesis universalista respecto de las razones jurídicas, admiten que el contenido de las normas jurídicas pueda ser precisado o completado a la luz de consideraciones morales. En realidad, independientemente del motivo

\footnotetext{
${ }^{37}$ Estoy de acuerdo con Moreso en que esta tesis no es patrimonio exclusivo de Dworkin o del Positivismo Jurídico Inclusivo.

${ }^{38}$ Se trata de la conocida paradoja de la irrelevancia moral del derecho y del gobierno. Cfr. C.S. Nino (1989), p. 370.
} 
por el cual se admita la revisión del contenido de las normas jurídicas ${ }^{39}$, la propia admisión de esa posibilidad supone que dichas normas no expresan razones invariables. La idea de la derrotabilidad de las normas jurídicas no es por sí misma problemática, mientras no se defienda simultáneamente una tesis contradictoria, esto es, la tesis del carácter universal o invariablemente relevante de las razones a las que ellas dan lugar. Soy consciente de que esta cuestión puede presentarse de diferentes maneras. Pero juzgo que todas ellas representan intentos infructuosos de evitar el dilema del carácter superfluo o injustificado del derecho, que se presenta a quien no distingue el problema de la universalidad de la relevancia de las normas jurídicas de la cuestión de la supremacía de la moral sobre el derecho.

Sin embargo, según Moreso:

no se trata de que las normas jurídicas sean derrotadas por la normas morales, sino que el contenido de las normas jurídicas ha de ser identificado mediante el uso del razonamiento moral.

Aceptemos por un momento esta propuesta. En este caso no cabe hablar de derrotabilidad de las normas jurídicas por parte de la moral sencillamente porque, por hipótesis, no hay posibilidad de identificar normas jurídicas antes de consultar a la moral. Es decir, se niega el presupuesto obvio del que he hablado antes: no hay posibilidad de distinguir las normas jurídicas de las normas morales. La identificación de las normas jurídicas que contienen defeaters evaluativos depende de las normas morales. Bajo esta reconstrucción, ciertamente, no cabe hablar de derrotabilidad de las normas jurídicas en virtud de la moral, pero tampoco cabe hablar de una relación entre derecho y moral. Una relación presupone necesariamente al menos dos elementos, y aquí este presupuesto obvio no se da, puesto que el derecho no existe con independencia de la moral. En la reconstrucción de

\footnotetext{
${ }^{39}$ Por ejemplo, a) cuando ofrecen una solución contrastante con la moral, b) cuando explícitamente remiten a la moral, o c) cuando en ellas aparecen conceptos evaluativos que, tal como propone Moreso, pueden ser interpretados como defeaters cuyo contenido sólo se puede establecer a través de un argumento moral.
} 
Moreso la presencia de un lenguaje evaluativo en el derecho lleva a la indistinción entre derecho y moral: el derecho es o requiere aquello que la moral indica. Obsérvese que en esta hipótesis tampoco se puede afirmar la "superioridad" de la moral sobre el derecho, porque esta tesis, al igual que la de la "derrotabilidad" del derecho en virtud de la moral, presupone la posibilidad de distinguir aquello que es derecho de aquello que es moral.

No estoy interesada en defender que estas ideas pueden también presentarse en términos de derrotabilidad. Lo que cuenta es que, en cualquier caso, se obtiene la misma conclusión. Un positivismo inclusivo como el que defiende Moreso, no es universalista respecto de las razones jurídicas. Una norma jurídica es relevante sólo cuando, y porque, su contenido coincide con la moral o cuando, y porque, la moral fija su contenido, i.e. es indistinguible de la moral.

A este punto es interesante volver al tema con el que he iniciado mi respuesta a los comentarios de Moreso. Discernir tres sentidos de universalidad sirve, por ejemplo, para esto, para mostrar cómo, respecto del derecho, algunas posiciones son universalistas sólo en un sentido trivial, semántico, o en un sentido lógico que les permite reconstruir las decisiones jurídicas como argumentos deductivos; pero en el único sentido en el que la idea de universalidad está relacionada con la relevancia práctica, con la generación de razones, no son universalistas, no aceptan la tesis según la cual las normas jurídicas establecen propiedades invariablemente relevantes. La tesis de Moreso es mucho más fuerte de lo que en principio parece. Desde el punto de vista de las razones para la acción su tesis no es que la moral tiene supremacía sobre el derecho. En sentido estricto, la tesis de la supremacía es perfectamente compatible con la defensa de la relevancia invariable de las razones jurídicas. Su tesis es que la única fuente de razones invariablemente relevantes es la moral.

\section{Consideraciones finales}

Es interesante notar que los trabajos de Caracciolo, Celano y Moreso 
presentan tres tesis bien diferenciadas en relación a la polémica universalismoparticularismo. Caracciolo defiende una posición universalista sin concesiones, insinuando que sólo desde este punto de vista se puede dar cuenta de la noción de normatividad y de justificación o, lo que es lo mismo, que desde un punto de vista particularista no es posible reconstruir una noción coherente de norma o generalización normativa aplicable en la justificación de casos concretos. Por su parte, Celano defiende la tesis exactamente opuesta. En su opinión, sólo una posición particularista puede reconstruir satisfactoriamente la noción de justificación y de aquello en lo que consiste una generalización normativa. A su criterio, el universalismo se apoya sobre una idea mal formada, razón por la cual es inadmisible. Por último, Moreso, argumenta a favor del universalismo en una versión restringida que permitiría superar el problema destacado por Celano.

Por mi parte, he intentado la defensa de algunas tesis que no coinciden en modo pleno con ninguna de estas propuestas y que, en algún sentido, pueden resultar "extravagantes". Con la esperanza de disipar esta impresión me he esforzado en mostrar las premisas que las justifican, a medida en que contestaba a las críticas que se me formulan. Creo que es útil resumir brevemente cuáles son estas tesis.

En mi trabajo "Razones y Normas" he sostenido que la discusión universalismo-particularismo puede ser vista como un desacuerdo filosófico o conceptual acerca de la noción de razón y de razonamiento práctico. Si se acepta esta lectura de la discusión, las tesis contrapuestas del universalismo y del particularismo deben ser vistas como tesis metateóricas, específicamente como tesis metafísicas ${ }^{40}$. Ahora bien, según he sostenido, el concepto universalista de razón presupone la existencia de un conjunto finito de normas universales válidas que relacionan un conjunto, también

\footnotetext{
${ }^{40}$ Estimo que el universalismo y el particularismo defienden tesis metafísicas contrapuestas respecto de la relevancia práctica de ciertas propiedades. En este sentido, J. Dancy, reconoce que la caracterización epistémica del particularismo puede llevar a confusión. Cfr. J. Dancy (1999), p. 144. Creo que lo mismo puede decirse en relación al universalismo.
} 
finito, de propiedades naturales con un conjunto de soluciones deónticas. Esta idea es fundamental porque permite subrayar que el desacuerdo universalismo-particularismo, si bien es una discrepancia sobre las características de las razones y del razonamiento práctico, involucra un desacuerdo ontológico acerca de si existen y en qué modo existen normas y razones para la acción. Dicho brevemente: una posición afirma y la otra niega que existan razones invariablemente relevantes, i.e. propiedades que de manera invariable consienten la obtención de consecuencias prácticas. A su vez, esta presentación, implícitamente, indica en qué no consisten las tesis del universalismo y el particularismo, y el respectivo desacuerdo. Concretamente: estamos frente a una discrepancia metaética y no de teoría moral acerca de qué propiedades deben ser consideradas razones o cómo debemos actuar. Justamente, la tesis metaética del universalismo avala la posibilidad y la plausibilidad de la idea de teoría moral normativa, i.e. de la identificación de un conjunto de normas universales válidas que sirvan de base a la justificación de nuestras acciones, mientras la tesis metateórica del particularismo rechaza la propia idea de teoría moral, concebida en este modo. Asimismo, y visto que estamos frente a dos ideas contrapuestas respecto de la existencia de principios normativos universales, también debería ser claro que las tesis del universalismo y el particularismo no son tesis epistémicas acerca de la invariabilidad o variabilidad de nuestras creencias o de nuestro conocimiento moral o jurídico, sino acerca de la invariabilidad o variabilidad de la relevancia práctica, moral o jurídica, que puedan tener las propiedades naturales. Ciertamente, ninguna de estas dos posiciones puede despreocuparse del problema epistémico acerca de cómo podemos acceder al conocimiento de la relevancia práctica de ciertas propiedades o, lo que es lo mismo, acerca de cómo se llega a creencias justificadas y verdaderas sobre las razones existentes. Sin embargo, si hay un desacuerdo a este nivel es exclusivamente explicable en virtud del desacuerdo acerca de cómo son las razones, específicamente, acerca de si tienen carácter variable o invariable, o de si tienen su fuente en circunstancias particulares o en normas universales. 
En este marco, a lo largo de esta respuesta, he insistido fundamentalmente en las siguientes tesis. La primera es que merece la pena distinguir tres sentidos en que la noción de universalidad resulta comprometida en este debate: en primer lugar, la universalidad entendida como generalidad semántica, en este caso, específicamente referida a los enunciados deónticos. Decir que una norma es universal en este sentido significa que regula una clase de casos. En segundo lugar, la universalidad lógica de los condicionales ode la forma condicional (forma, ésta, que no se usa sólo para expresar normas, pero que normalmente se acepta a este fin). Decir que una norma es universal en este sentido significa que le son aplicables las reglas lógicas del refuerzo del antecedente y del modus ponens. En tercer lugar, la universalidad en sentido práctico, es decir, la idea de invariabilidad de la relevancia. Decir que una norma es universal en este sentido significa que genera una razón invariable para la acción. Esta última noción, según he dicho, implica la validez de los contenidos normativos expresados mediante la forma lógica del condicional universal ${ }^{41}$.

La distinción entre el segundo y el tercer sentido de universalidad puede parecer forzada, sin embargo, sigo pensando que es significativa. En primer lugar, porque el particularismo se define exclusivamente como la negación del tercer sentido de universalidad, i.e. la negación de la invariabilidad de la relevancia práctica, que a su vez implica la negación de la validez de normas universales ${ }^{42}$. En segundo lugar, porque parte de mi objetivo ha sido aplicar

\footnotetext{
${ }^{41}$ Asimismo, es la única que implica la idea de universalización que, si bien recibe diversas formulaciones en la filosofía moral, puede expresarse a grandes rasgos del siguiente modo: si un atributo tiene relevancia práctica en una situación, la tiene en toda otra situación que sea similar (en modo relevante).

${ }^{42}$ Es claro que el particularismo no tiene por qué negar la universalidad lógica de los condicionales en cualquier otro ámbito de razonamiento que no sea al razonamiento "práctico". Adicionalmente, en mi trabajo he argumentado que, en sentido estricto, podría aceptar la aplicación de las reglas del refuerzo del antecedente y del modus ponens a la normas, negando toda relevancia práctica a las conclusiones que formalmente se pueden extraer a través de tales razonamientos. Sin embargo, y tal como he sostenido, no creo que ésta sea la forma adecuada de presentar el particularismo. Esta posición, al negar la invariabilidad de la relevancia práctica de las razones está diciendo que, desde un punto de vista lógico, la reconstrucción adecuada de las generalizaciones deónticas no es la del condicional estricto, i.e. que nuestro razonamiento a partir de ellas no es monotónico.
} 
las tesis del universalismo y del particularismo al ámbito jurídico y allí resulta importante no confundir estos sentidos de universalidad cuyo discernimiento parece caprichoso en el ámbito moral. Especialmente porque es usual atribuir a las normas jurídicas una estructura lógica universal sin reconocer relevancia práctica universal a las propiedades que ellas mencionan en sus antecedentes.

La noción de relevancia práctica, en este contexto, no coincide con la noción de relevancia tal como se usa en parte importante de la teoría jurídica ${ }^{43}$. Una propiedad es relevante si establece o marca una diferencia en nuestro razonamiento práctico; concretamente, si ella es suficiente o contribuyente (i.e., condición necesaria de una condición suficiente) para obtener una consecuencia deóntica. La relevancia, así concebida, es la propiedad definitoria de las razones. Algo es una razón si y sólo si es relevante. Por este motivo, debería ser claro que el desacuerdo entre universalismo y particularismo versa, no sobre si existen propiedades relevantes (i.e. suficientes o contribuyentes) para aplicar un predicado deóntico, sino sobre la invariabilidad de la relevancia de dichas propiedades o, lo que es lo mismo, sobre la existencia de normas universales válidas o justificadas.

Una segunda tesis inusual sobre la que me he detenido en estas páginas se refiere a que las normas, en sus consecuentes, establecen deberes no necesariamente concluyentes o finales. En otras palabras, es posible distinguir normas universales absolutas, o concluyentes, que establecen deberes insuperables, o finales, respectivamente, y normas universales no absolutas, ni concluyentes, que establecen deberes superables ${ }^{44}$. Aceptando esta

\footnotetext{
${ }^{43}$ Me refiero a la noción propuesta en C. Alchourrón y E. Bulygin (1971), profundamente analizada en J. Rodríguez (1999). Tal como aquí la analizo, la noción de relevancia práctica sí está parcialmente relacionada con lo que este último autor identifica con un sentido fuerte según el cual una propiedad es calificada como relevante justamente si ella es la razón por la cual se aplica la consecuencia deóntica. Véase J. Rodríguez (1999), p. 360.

${ }^{44}$ Tomo esta distinción de Shafer Landau quien se refiere a normas absolutas y normas prima facie. Yo he preferido evitar la expresión "prima facie" para no introducir la ambigüedad que ella encierra. Sin embargo, sobre todo al referirme al trabajo de Caracciolo, será preciso retomar esta expresión.
} 
distinción, me he concentrado exclusivamente en normas universales que establecen deberes superables. Esta estrategia, en primer lugar, me ha permitido usar la universalidad de la forma lógica para expresar, sin ambigüedad, la invariabilidad de la relevancia de las propiedades mencionadas en el antecedente de las normas, es decir sin confundirla con el carácter superable o insuperable de los deberes mencionados en el consecuente. En segundo lugar, me ha permitido hacer explícita la idea según la cual ser universalista no significa defender la ausencia de conflictos jurídicos o morales. Es decir, defender la existencia de principios jurídicos o morales universales no significa sostener que ellos siempre determinan aquello que concluyentemente se debe hacer, y esto es tanto como decir que la tesis universalista es compatible con la tesis de la parcial indeterminación del derecho o de la moral.

De este modo, se evitan lo que a mi juicio son dos defectos de las posiciones que aceptan sólo normas absolutas. En primer lugar, estas posiciones tornan ambigua la forma lógica del condicional universal, la que, necesariamente, expresa tanto la idea de invariabilidad de la relevancia (de las propiedades expresadas en el antecedente) como la de insuperabilidad o conclusividad de los deberes (expresados en el consecuente). En segundo lugar, tornan paradójica la noción de conflicto entre razones o deberes puesto que, o bien desaparece al ser reducida a un problema epistémico de identificación de la norma que establece el deber final o concluyente, o bien se presenta como un dilema entre deberes concluyentes contrastantes ${ }^{45}$.

Esta idea, nuevamente, cobra mayor interés cuando se proyecta al ámbito jurídico. Sostener que, si el derecho da razones, ellas son invariables no significa decir que el derecho siempre ofrece razones, ni que las que

${ }^{45}$ En realidad, cabe precisar si el consecuente establece deberes últimos, en el sentido de insuperables, o últimos en el sentido de concluyentes. En el primer caso, todo conflicto es un dilema (por definición, ninguno de los dos deberes en cuestión puede superar al otro), en el segundo caso, los conflictos son imposibles, puesto que la noción deviene auto-contradictoria, (dos deberes que están en conflicto, por definición, no son concluyentes). 
ofrece determinan siempre lo que se debe concluyentemente hacer ${ }^{46}$. Por ejemplo, un sistema jurídico puede establecer con claridad que el honor de las personas debe ser protegido, pero que dicho deber cede en el caso en que esté en juego el derecho a acceder a información verídica. A su vez, puede establecer que la libertad de expresión merece siempre respeto, pero que su valor no es absoluto y cede en situaciones especiales en que esté en juego la defensa y la seguridad del Estado. Ahora bien, si este sistema, en el que explícitamente se admite que el honor y la libertad de expresión son propiedades relevantes pero de peso no absoluto, no ofrece criterios que permitan establecer una jerarquía entre ellos, existirá un genuino conflicto en aquellos casos en que una acción sea a la vez ejercicio de la libertad de expresión pero implique una lesión del honor de alguien. Este conflicto quizás pueda ser fácilmente resuelto aplicando criterios extra-jurídicos, pero no queda bien representado ni como un problema epistémico o interpretativo (visto que, por hipótesis, no hay un criterio de preferencia entre ellos) ni como un dilema entre deberes últimos (visto que, por hipótesis, no son deberes absolutos ni concluyentes).

Del mismo modo que en mi propuesta inicial, en esta respuesta he reiterado que tanto la tesis del universalismo como la del particularismo son posibles y que, en ese sentido, tanto Caracciolo como Celano se equivocan cuando dirigen toda su argumentación a mostrar que la posición no favorecida por ellos presenta un defecto insuperable. Desde el punto de vista de la estrategia argumentativa -aunque no desde el punto de vista del contenido de su propuesta-, creo que Moreso lleva razón cuando articula la defensa de una posición, no porque la alternativa sea irremediablemente fallida sino

\footnotetext{
${ }^{46}$ Concretamente, por ejemplo, decir que el derecho ofrece razones universales o invariablemente relevantes es compatible con sostener que el derecho está parcialmente indeterminado en virtud de problemas semánticos (i.e. de vaguedad), problemas epistémicos respecto de la interpretación o identificación de normas completas (de normas que expresan una condición suficiente), problemas axiológicos (lagunas axiológicas), y problemas lógicos (lagunas normativas y contradicciones).
} 
sencillamente porque, en su opinión, es la que mejor capta el tipo de razonamiento que le interesa reconstruir. Asimismo, una vez más, no me he concentrado en la defensa de ninguna de estas tesis metateóricas, justamente porque (bajo la hipótesis de que ninguna de ellas presenta problemas insuperables) no creo que tenga sentido favorecer un concepto por sí mismo sino en relación a determinados objetivos o problemas teóricos. Coherente con esta afirmación y sólo a título de ejemplo, he sostenido que la noción universalista de razón está presupuesta en nuestro concepto contemporáneo de derecho y, en tal medida, es esencial para su comprensión. Sin embargo, estaría de acuerdo con Celano en que nuestra forma ordinaria de razonar, probablemente, queda mejor explicada desde un punto de vista particularista. No he justificado aquí estas afirmaciones, pero si lo que he dicho es correcto, ello presupone lo que sí he intentado mostrar: que ambas nociones son lógicamente posibles y podrían, dependiendo de cómo sean o se modifiquen efectivamente nuestras actitudes y prácticas sociales, captar "nuestra" forma de razonamiento en distintos ámbitos.

\section{Referencias}

Alchourrón, Carlos (1996), "Detachment and Defeasibility in Deontic Logic”, Studia Logica 57, pp. 5-18.

Alchourrón, Carlos y Bulygin, Eugenio (1971), "Normative Systems", Springer Verlag, Wien/New York.

Bayón, Juan Carlos y Rodríguez, Jorge (2003), "Relevancia en la justificación de las decisiones judiciales", Universidad Externado de Colombia, Bogotá.

Brown, H. (1999), "Why do Conceptual Analysts disagree?", Metaphilosophy, Vol.30, $\mathrm{N}^{\circ} 1 / 2$, pp. 33-59. 
Dancy, Jonathan (1993), "Moral Reasons”, Blackwell, Oxford.

Dancy, Jonathan (1999) "Defending Particularism", Metaphilosophy, vol. 30, Nos.1/2, pp.25-32.

Dancy, Jonathan (2004), "Ethics Without Principles", Clarendon Press, Oxford, cap. 8.

Hart, Herbert Lionel Adolphus (1961- 1994), "The Concept of Law", Clarendon, Oxford.

Kagan, S. (1988) “The Additive Fallacy”, Ethics 99, 55-31.

Nino, Carlos Santiago (1989), "Ética y derechos humanos", Ariel, Barcelona.

Raz, Joseph (2001), "Notes on Value and Objectivity", Brian Leiter (ed.), Objectivity in Law and Morals, Cambridge U.P., Cambridge.

Raz, Joseph (2004), "Can There be a Theory of Law?", Guide to Philosophy of Law, Blackwell, Oxford.

Rodríguez, Jorge (1999), "Lagunas axiológicas y relevancia normativa", Doxa 22, pp. 348-369.

Schauer, Frederick (1991), "Playing by the Rules. A Philosophical Examination of Rue-Base Decision-Making in Law and in Life", Clarendon, Oxford.

Shafer-Landau, Russ (1997),“Moral Rules”, Ethics 107, pp- 584-611.

Searle, John (1991), "Answer to Critics", en Ernest Lepore and Robert van Gulick (eds.), John Searle and His Critics, Blackwell, Cambridge, Mass.

Tännsjö, T. (1995), "In Defense of Theory in Ethics", Canadian Journal of Philosophy, vol. 25, N4, 571-594. 